NBER WORKING PAPER SERIES

\title{
MPC HETEROGENEITY IN EUROPE: SOURCES AND POLICY IMPLICATIONS
}

\author{
Miguel Ampudia \\ Russell Cooper \\ Julia Le Blanc \\ Guozhong Zhu \\ Working Paper 25082 \\ http://www.nber.org/papers/w25082 \\ NATIONAL BUREAU OF ECONOMIC RESEARCH \\ 1050 Massachusetts Avenue \\ Cambridge, MA 02138 \\ September 2018
}

Russell Cooper thanks the European Central Bank for supporting this research. Thanks to David Lander and Sebastian Rast for research assistance on this project. Comments from Jirka Slacalek, Joao Cocco, Chris Carroll, Ernesto Pasten, Frederique Savignac, Gianluca Violante, and participants at the HFCN meeting in Bratislava, the HFCN research workshop, the HEC meeting in Moscow, the Joint European Central Bank/Centre for Economic Policy Research Workshop on Household Heterogeneity in Macroeconomics 2018, CREST, the Central Bank of Chile research seminar, the International Conference on Macroeconomic Analysis and International Finance, and the Central Bank of Ireland household Finance Conference and European University Institute are greatly appreciated. The views expressed in this paper are those of the authors and do not necessarily reflect the position of the National Bureau of Economic Research.

NBER working papers are circulated for discussion and comment purposes. They have not been peerreviewed or been subject to the review by the NBER Board of Directors that accompanies official NBER publications.

(C) 2018 by Miguel Ampudia, Russell Cooper, Julia Le Blanc, and Guozhong Zhu. All rights reserved. Short sections of text, not to exceed two paragraphs, may be quoted without explicit permission provided that full credit, including $\odot$ notice, is given to the source. 
MPC Heterogeneity in Europe: Sources and Policy Implications

Miguel Ampudia, Russell Cooper, Julia Le Blanc, and Guozhong Zhu

NBER Working Paper No. 25082

September 2018, Revised April 2020

JEL No. E21,E52

\begin{abstract}
$\underline{\text { ABSTRACT }}$
This paper studies the implications of household financial choices for the effects of monetary policy on consumption. Based on data from four major euro area countries, the paper estimates the key structural parameters using a simulated method of moments approach to match moments related to asset market participation rates, portfolio shares and wealth to income ratios by education and country. The policy functions based upon the estimation are used to characterize the distributions of the marginal propensity to consume across heterogenous households for each of the four countries. Due to this heterogeneity in consumption responses, monetary policy, operating through its effects on household income and asset market returns, has a differential impact on individuals within and across countries. Generally, poor households respond more to the income variations produced by monetary policy innovations while rich households respond more to policy-induced variations in stock returns. Monetary policy has a larger impact on consumption in Italy and Spain compared to France and Germany.

Miguel Ampudia

Sonnemannstr. 20

60314 Frankfurt am Main

Germany

Miguel.Ampudia@ecb.int

Russell Cooper

Department of Economics

European University Institute

Villa La Fonte

Via delle Fontanelle 18

I-50014 San Domenico di Fiesole (FI)

ITALY

and NBER

russellcoop@gmail.com

Julia Le Blanc

Deutsche Bundesbank

Wilhelm Epstein Strasse 14

60431 Frankfurt am Main

Germany

julia.le.blanc@bundesbank.de

Guozhong Zhu

University of Alberta

Edmonton, Alberta

CANADA

guozhong@ualberta.ca
\end{abstract}




\title{
MPC Heterogeneity and the Dynamic Response of Consumption to Monetary Policy*
}

\author{
Miguel Ampudia†, Russell Cooper, Julia Le Blancફ, and Guozhong Zhuף
}

March 5, 2020

\begin{abstract}
This paper studies the implications of household financial choices for the effects of monetary policy on consumption. Based on data from four major euro area countries, the paper estimates the key structural parameters using a simulated method of moments approach to match moments related to asset market participation rates, portfolio shares and wealth to income ratios by education and country. The policy functions based upon the estimation are used to characterize the distributions of the marginal propensity to consume across heterogenous households for each of the four countries. Due to this heterogeneity in consumption responses, monetary policy, operating through its effects on household income and asset market returns, has a differential impact on individuals within and across countries. Generally, poor households respond more to the income variations produced by monetary policy innovations while rich households respond more to policy-induced variations in stock returns. Monetary policy has a larger impact on consumption in Italy and Spain compared to France and Germany.
\end{abstract}

Keywords: heterogeneity, marginal propensity to consume, monetary policy

\section{Motivation}

This paper studies a central question in monetary economics: how does monetary policy influence consumption? Over recent years, this traditional question of the link between monetary policy and consumption has been reexamined through the lens of models of heterogeneous households whose consumption decisions depend, in part,

\footnotetext{
*Russell Cooper thanks the European Central Bank for supporting this research. Thanks to David Lander and Sebastian Rast for research assistance on this project. Comments from Jirka Slacalek, Joao Cocco, Chris Carroll, Ernesto Pasten, Frédérique Savignac, Gianluca Violante, and participants at the HFCN meeting in Bratislava, the HFCN research workshop, the HEC meeting in Moscow, the Joint European Central Bank/Centre for Economic Policy Research Workshop on Household Heterogeneity in Macroeconomics 2018, CREST, the Central Bank of Chile research seminar, the International Conference on Macroeconomic Analysis and International Finance, and the Central Bank of Ireland household Finance Conference and European University Institute are greatly appreciated.

${ }^{\dagger}$ European Central Bank, Miguel.Ampudia@ecb.int

${ }^{\ddagger}$ Department of Economics, the Pennsylvania State University, the European University Institute and the NBER, russellcoop@gmail.com

$\S$ Deutsche Bundesbank, Julia.Le.Blanc@bundesbank.de

`School of Business, University of Alberta, guozhong@ualberta.ca
} 
on their asset portfolio. A leading example of this approach is Kaplan, Moll, and Violante (2018). Our paper follows this perspective and focuses on the role of heterogeneity across households in the analysis of monetary policy. Focusing on four euro area countries, Germany, Spain, France and Italy, this paper studies how ex ante heterogeneity in income and education of households leads to ex post heterogeneity in financial choices, which in turn generates differential responses to income shocks and asset return shocks induced by monetary policy.

Our paper differs from the literature in one critical way: the estimation of both key parameters and the responses of income and stock returns to monetary innovations. To understand our approach and the role of estimation, suppose one decomposes the aggregate response of consumption to monetary policy into three parts: (i) the individual response to income and return variations, (ii) the distribution of agents across income, wealth and asset participation states and (iii) the response of income and asset returns to monetary policy. ${ }^{1}$ First, using a simulated method of moments approach, we estimate country-specific household preferences. From this, we determine the consumption response to income and return innovations at the household level for each country. Second, the cross sectional distribution, in particular its evolution, is determined by the underlying dynamics at the household level based upon the estimated parameters. Third, the impact of monetary policy on households through income and asset return channels is taken from estimated impulse response functions. This approach allows us to display the full dynamic response of consumption across heterogeneous households to the data-consistent effects of monetary innovations.

There are three steps in the analysis. The initial step is the estimation of household preferences, stock market participation costs and portfolio adjustment costs by education and country. The estimation uses a simulated method of moments approach based on a life-cycle model of household financial choice. The model includes both stock market participation and portfolio adjustment decisions. ${ }^{2}$ Both of these discrete choices are relevant for understanding household financial decisions and the impact of monetary innovations. ${ }^{3}$

Here we find that low income, low education households have the largest consumption response to income changes induced by monetary innovations. High income, high education households also respond to monetary policy through induced changes in asset returns. This pattern of responses is common across countries.

The second step is the characterization of the distributions of the marginal propensity to consume (MPC) across heterogeneous households by country. ${ }^{4}$ This distribution is obtained by simulating the response to income and return shocks using the estimated household-level policy functions. ${ }^{5}$ The resulting country-specific MPC distributions are used as inputs in the monetary policy analysis with heterogeneous households facing stock market participation and adjustment frictions. ${ }^{6}$

\footnotetext{
${ }^{1}$ This decomposition is made formal in equation (13) and forms the basis of our analysis.

${ }^{2}$ The model does not include an explicit housing channel which is emphasized by Cloyne, Ferreira, and Surico (2020) and Hintermaier and Koeniger (2018) among others. The treatment of housing the empirical application is explained in detail below.

${ }^{3} \mathrm{~A}$ discussion of these estimation results relative to the literature is postponed until the presentation of our estimates.

${ }^{4}$ Carroll, Slacalek, and Tokuoka (2014) look across EU countries and generate an MPC distribution in an alternative setting which does not emphasize participation and adjustment frictions. Their focus is on the relationship between the wealth distribution and the aggregate MPC.

${ }^{5}$ Thus the MPC distribution is not estimated from an auxiliary equation but is instead consistent with the estimated model.

${ }^{6}$ A leading example in the European context would be Kaplan, Violante, and Weidner (2014). Guerrieri and Mendicino (2018) estimate the MPC across euro area countries from quarterly Household Sector Report data and conclude that the cross-country averages of MPC out of financial wealth are between 0.7 and 4.5 cents per euro.
} 
Finally, the estimated model is used to study the impact of monetary policy on consumption. Similar to Kaplan, Moll, and Violante (2018) and Auclert (2017), a monetary policy innovation influences consumption through (nonasset) income and stock market returns. Given the heterogeneity across households within a country, there is a non-degenerate distribution of consumption responses to monetary policy innovations. The aggregate response will depend on both the nature of the monetary shock and its magnitude. The latter point arises from the nonlinear response of households to income and return shocks. Monetary policy will consequently have distributional effects in terms of households' income and wealth as in Ampudia, Georgarakos, Slacalek, Tristani, Vermeulen, and Violante (2018), Casiraghi, Gaiotti, Rodano, and Secchi (2018) and Coibion, Gorodnichenko, Kueng, and Silvia (2017).

We find that the main effects of monetary policy on consumption are largely channeled through relatively poor (low income) households. This reflects two factors: (i) the income of poor households reacts more intensively to monetary shocks and (ii) it is precisely these households who have the largest marginal propensity to consume (MPC). But this response of consumption induced by income variations is very much country-specific, in part because the income response to monetary shocks is not uniform across countries.

There is an additional stock return channel, operating through the effects of monetary innovations on stock prices. This channel clearly only influences the consumption of asset market participants. This is where the differences in asset market participation across countries is relevant. Although these stock market participants have more modest MPCs out of financial income, there is nonetheless a consumption response through this channel.

Put together, these channels induce a U-shaped consumption response to monetary shocks relative to the income distribution. The lowest income level households have the highest MPC out of income and respond to the effects of monetary policy through income. The highest income group is more likely to participate in stock markets and responds to the effects of monetary policy on stock returns. This pattern is most visible in Germany and France. ${ }^{7}$

The paper is organized as follows. Section 2 presents basic data facts. Section 3 introduces the life-cycle optimization problem of households. Section 4 shows the exogenous processes that are used as inputs in the model, as well as the moments used to identify key model parameters. Section 5 discusses the results of structural estimation. Section 6 studies MPC distributions of the four countries, and section 7 quantitatively evaluates the effects of monetary policy on consumption. Section 8 concludes and provides a discussion of potential future studies.

\section{Data Facts}

This section presents facts about household financial decisions in Germany, Spain, France and Italy, providing motivation for our analysis and the model of dynamic household choices. The data come from the Household Finance and Consumption Survey for the 2008-2010 period. ${ }^{8}$

As shown in Table 1, we focus on the financial portfolio of the household and its relation to income defined as the labor income of a household plus transfers from the government (e.g. unemployment benefits). Participation is defined by the non-zero holding of stocks, either directly or indirectly through mutual funds and pension plans.

\footnotetext{
${ }^{7}$ These results are clear from the bottom panel of Table 16.

${ }^{8}$ See https://www.ecb.europa.eu/pub/economic-research/research-networks/html/researcher_hfcn.en.html.
} 
The table also displays the median financial wealth to income ratio. The moments are presented by education group: college or no college attainment. As discussed in Cooper and Zhu (2015), education potentially matters both in terms of differences in income processes, patience and for asset market participation and adjustment costs through financial literacy.

Table 1: Household Finance Facts by Education across Countries

\begin{tabular}{ccccccccc}
\hline \hline & \multicolumn{2}{c}{ Germany } & \multicolumn{2}{c}{ Spain } & \multicolumn{2}{c}{ France } & \multicolumn{2}{c}{ Italy } \\
\hline edu & low & high & low & high & low & high & low & high \\
\hline participation & 45.4 & 66.7 & 23.2 & 47.0 & 39.2 & 56.0 & 19.5 & 36.0 \\
stock share & 50.0 & 44.7 & 50.8 & 45.1 & 50.0 & 44.5 & 47.3 & 37.6 \\
W/I & 0.350 & 0.749 & 0.180 & 0.399 & 0.303 & 0.552 & 0.287 & 0.519 \\
avg. age & 52.5 & 53.0 & 54.4 & 47.0 & 54.8 & 43.7 & 56.7 & 51.0 \\
sample size & 2085 & 1480 & 3988 & 2209 & 10833 & 4173 & 7013 & 938 \\
\hline \hline
\end{tabular}

This table displays the asset market participation rate (in percent), the average share of stocks over total liquid assets (for participants, in percent), the median financial wealth-to-income ratio (w/I) for households in each country by educational attainment, low (no college) and high (college). Standard errors for these moments are shown in Table 17. Data source: HFCS first wave.

Participation rates in stocks are well below $100 \%$ in all countries. These rates are somewhat higher for college graduates. Still, there is wide dispersion across country/education level groups: participation is less than $20 \%$ in Italy for the low education group and reaches almost $67 \%$ in Germany for college graduates. As established later, these differences in participation rates translate into differences in response to monetary policy, particularly through asset prices.

For those who participate in the stock market, the share of stocks in their portfolio averages between $40 \%$ and $50 \%$. There are not large differences across countries. Further, differences between the two education groups are small, with households without a college degree holding larger shares than college educated ones. The median financial wealth to income ratio is less than 1 for all countries and is higher for the higher education groups.

These are important features that a model of household finance must take into account. Our model does so by introducing two frictions into the standard life-cycle model: a cost of asset market participation and a portfolio adjustment cost.

The literature on stock market participation has concluded that some level of fixed costs are necessary to improve the empirical fit of life-cycle models. For example, Vissing-Jorgensen (2002), Gomes and Michaelides (2005), Alan (2006) and Cooper and Zhu (2015) study life-cycle models with portfolio choice and fixed stock market entry cost to explain the low stock market participation rates and/or moderate equity holdings of stock market participants. The differences in portfolios across countries are studied in Christelis, Georgarakos, and Haliassos (2013), as well as in Guiso, Haliassos, and Jappelli (2003).

Our analysis is motivated by these same dimensions of household financial decisions. But our approach and hence insights differ both due to the emphasis on estimation of key parameters and the consequent use of these estimates for policy evaluation. 


\section{Household Dynamic Optimization}

This section presents the household dynamic optimization problem, drawing on Cooper and Zhu (2015). A key element is the presence of non-convexities due to both participation and adjustment costs. ${ }^{9}$ As we shall see, these elements of the model are important not only for matching the moments of household financial choices but also influence the household response to monetary policy.

The purpose of this section is two-fold. First, the estimation of dynamic financial choices at the household level is of interest in its own right: we want to know what the key country-specific features are that explain the different patterns shown in Table 1. Second, we want to shed light on how the differences in financial decisions, captured through the estimated parameters, influence the effects of monetary policy.

The household optimization problem entails a number of decisions. First, there is the choice of asset market participation. ${ }^{10}$ Second, conditional on participating the agent can choose whether or not to adjust the portfolio, i.e. to change the amount of investment in the stock market. In the case of non-adjustment, we assume the return on stocks is automatically reinvested. Finally, there is a continuous choice over consumption and saving.

A household works for $T^{r}$ periods and survives up to $T>T^{r}$ periods. The two phases of life are distinguished by income risk. Income is stochastic during the working life. Once the households retires, income is deterministic and country-specific.

The model does not include durable goods, such as housing. ${ }^{11}$ Instead, the effects of home ownership are controlled in the regression that generates the moments we match. Adding housing separately as another state variable is computationally very burdensome. There are alternatives. Kaplan, Moll, and Violante (2018) include housing in illiquid assets, assuming households hold a fixed fraction of total illiquid assets as housing. This approach makes asset market participation and home ownership, as well as trading frictions, difficult to separate. Cooper and Zhu (2015) treat housing as bond holdings (their section 5.2.1) which does separate home and stock ownership but ignores costs of trading houses.

The optimization problem discussed below is generic. The indices indicating country and education level are dropped. It is understood that the exogenous income process is both country and education specific. Further, the parameters to be estimated are country-specific as well.

\subsection{Participants}

$\Omega=(y, A)$ represents the current state of the household where $y$ is current labor income and $A=\left(A^{b}, A^{s}\right)$ is the current value of the holdings of bonds and stocks respectively. A household that is currently holding stocks, i.e. $A^{s}>0$, is a participant and chooses between (i) portfolio adjustment, (ii) no portfolio adjustment and (iii) exiting the asset markets by selling all stocks. The discrete choice of an age $t$ participant is given by:

\footnotetext{
${ }^{9}$ Kaplan, Moll, and Violante (2018) includes a version of these frictions while Auclert (2017) does not.

${ }^{10}$ The model abstracts from the distinction between direct and indirect holdings of stocks, and thus participation can be understood in its broadest sense, i.e., including both direct and indirect participation.

${ }^{11}$ In contrast, Hintermaier and Koeniger (2018) emphasizes home ownership differences across countries and links these with monetary policy effects. Their model includes adjustment costs for housing, but it does not focus on asset market participation and portfolio adjustment as in our model.
} 


$$
v_{t}(\Omega)=\max \left\{v_{t}^{a}(\Omega), v_{t}^{n}(\Omega), v_{t}^{x}(\Omega)\right\}
$$

for all states $\Omega$.

A household choosing to adjust the portfolio selects the amount of stocks and bonds to solve:

$$
v_{t}^{a}(\Omega)=\max _{A^{b^{\prime}} \geq \underline{A}^{b}, A^{s^{\prime}} \geq 0}\left\{(1-\beta) c^{1-1 / \theta}+\beta\left[\left(1-\nu_{t+1}\right)\left(E_{t} v_{t+1}\left(\Omega^{\prime}\right)^{1-\gamma}\right)^{\frac{1}{1-\gamma}}+\nu_{t+1}\left(E_{t} B\left(A^{\prime}\right)^{1-\gamma}\right)^{\frac{1}{1-\gamma}}\right]^{1-1 / \theta}\right\}^{\frac{1}{1-1 / \theta}}
$$

s.t.

$$
\begin{gathered}
c=y+T R+\sum_{i=b, s} R^{i} A^{i}-\sum_{i=b, s} A^{i^{\prime}}-F \\
A^{\prime}=R^{b} A^{b^{\prime}}+R^{s^{\prime}} A^{s^{\prime}} \\
T R=\max \left\{0, \underline{c}-\left(y+\sum_{i=b, s} R^{i} A^{i}\right)\right\} .
\end{gathered}
$$

where the expectation is taken with respect to future income and asset returns. The probability of surviving to the next period is $\nu_{t+1}$ which depends on both age and, implicitly, the education of the agent. Following Epstein and Zin (1989) and Weil (1990) we assume a recursive utility representation. ${ }^{12}$ Here $\gamma$ captures the attitude of the agent towards risk and $\theta$ is the elasticity of intertemporal substitution. With this specification, the two key aspects of household choices are estimated independently.

There is a consumption floor of $\underline{c}$ representing a transfer from the government to the household. This feature of the model is taken from Hubbard, Skinner, and Zeldes (1995) and DeNardi, French, and Jones (2010). In the empirical implementation, this floor includes transfers beyond unemployment insurance and the transfers included in the income measure. Based upon the results reported in Cooper and Zhu (2015), the consumption floor is important for matching the wealth-to-income ratios of low education households.

$B\left(A^{\prime}\right)$ in equation (2) is the value of leaving a bequest of size $A^{\prime}$, including the liquidated value of stocks as shown in equation (4). The household chooses a bequest portfolio without knowing the stock return that will determine the full value of the inheritance. The bequest function is given by:

$$
B\left(A^{\prime}\right)=L\left(\phi+A^{\prime}\right)
$$

The curvature over the bequests, parameterized by $\gamma$, appears through equation (2). Here $\phi>0$ measures to what extent the bequest is luxurious. It also allows for $A^{\prime}=0$ while keeping $B^{\prime}(0)^{1-\gamma}$ a finite number.

In this problem, there is a lower bound to bond holdings, $\underline{A}^{b}$, which can be negative to allow borrowing. When this lower bound is binding, households are liquidity constrained. Note that this constraint can bind for participants who have illiquid stock holdings so that these (rich) agents too are liquidity constrained. Short sales of stocks are not allowed.

The $F$ in equation (3), the budget equation, represents the cost of portfolio adjustment which includes fees paid as well as time costs incurred. In Bonaparte, Cooper, and Zhu (2012) and Cooper and Zhu (2015), this cost

\footnotetext{
${ }^{12}$ As reported in Cooper and Zhu (2015), a recursive utility formulation fits the moments for the US best.
} 
is used, in part, to match portfolio adjustment rates. But no data exists on adjustment rates for the asset market participants in our sample countries. This parameter is identified through portfolio composition: a high value of $F$ discourages households to participate in asset markets or lower the share of stocks in total wealth for participants, thus helping to match these aspects of the data for each country. As discussed further below, this illiquidity of stock investment can create a high MPC even for wealthy households.

If the household chooses not to adjust its portfolio, then the cost $F$ is avoided and there is re-optimization over consumption and bond holdings. The household chooses bonds to maximize:

$$
v_{t}^{n}(\Omega)=\max _{A^{b} \geq \underline{A}^{b}}\left\{(1-\beta) c^{1-1 / \theta}+\beta\left[\left(1-\nu_{t+1}\right)\left(E_{t} v_{t+1}\left(\Omega^{\prime}\right)^{1-\gamma}\right)^{\frac{1}{1-\gamma}}+\nu_{t+1}\left(E_{t} B\left(A^{\prime}\right)^{1-\gamma}\right)^{\frac{1}{1-\gamma}}\right]^{1-1 / \theta}\right\}^{\frac{1}{1-1 / \theta}}
$$

s.t.

$$
\begin{gathered}
c=y+T R+R^{b} A^{b}-A^{b \prime} \\
A^{s \prime}=R^{s} A^{s} \\
A^{\prime}=R^{b} A^{b^{\prime}}+R^{s^{\prime}} A^{s^{\prime}} \\
T R=\max \left\{0, \underline{c}-\left(y+\sum_{i=b, s} R^{i} A^{i}\right)\right\} .
\end{gathered}
$$

Here we assume that if there is no portfolio rebalancing, any return on stocks is automatically put into the stock account, i.e. $A^{s \prime}=R^{s} A^{s}$.

A household currently participating may choose to end its stock holdings. Though there is no flow cost of participating, a household will exit asset markets when a large income shock leads to the liquidation of stock holdings. The value from exiting the asset markets is given by:

$$
v_{t}^{x}(\Omega)=\max _{A^{b^{\prime}} \geq \underline{A}^{b}}\left\{(1-\beta) c^{1-1 / \theta}+\beta\left[\left(1-\nu_{t+1}\right)\left(E_{t} w_{t+1}\left(\Omega^{\prime}\right)^{1-\gamma}\right)^{\frac{1}{1-\gamma}}+\nu_{t+1}\left(E_{t} B\left(A^{\prime}\right)^{1-\gamma}\right)^{\frac{1}{1-\gamma}}\right]^{1-1 / \theta}\right\}^{\frac{1}{1-1 / \theta}}
$$
s.t.

$$
\begin{gathered}
c=y+T R+\sum_{i=b, s} R^{i} A^{i}-A^{b \prime} \\
A^{\prime}=R^{b} A^{b^{\prime}} \\
T R=\max \left\{0, \underline{c}-\left(y+\sum_{i=b, s} R^{i} A^{i}\right)\right\} .
\end{gathered}
$$

where $w_{t+1}\left(\Omega^{\prime}\right)$ denotes the value function of stock market non-participants given the future state $\Omega^{\prime}$.

\section{$3.2 \quad$ Non-Participants}

A household currently not holding stocks can, at a cost, enter into asset markets. Or the household can remain a non-participant. The values for this decision are given by:

$$
w_{t}(\Omega)=\max \left\{w_{t}^{n}(\Omega), w_{t}^{p}(\Omega)\right\}
$$


for all $\Omega$.

Even if the household remains a non-participant, it can adjust its bond account in response to income shocks. The optimization problem of a non-participant choosing not to enter the asset markets is:

$$
w_{t}^{n}(\Omega)=\max _{A^{b^{\prime}} \geq \underline{A}^{b}}\left\{(1-\beta) c^{1-1 / \theta}+\beta\left[\left(1-\nu_{t+1}\right)\left(E_{t} w_{t+1}\left(\Omega^{\prime}\right)^{1-\gamma}\right)^{\frac{1}{1-\gamma}}+\nu_{t+1}\left(E_{t} B\left(A^{\prime}\right)^{1-\gamma}\right)^{\frac{1}{1-\gamma}}\right]^{1-1 / \theta}\right\}^{\frac{1}{1-1 / \theta}}
$$

for all $\Omega$. The budget constraints are:

$$
\begin{gathered}
c=y+T R+R^{b} A^{b}-A^{b \prime} \\
A^{\prime}=R^{b} A^{b^{\prime}} \\
T R=\max \left\{0, \underline{c}-\left(y+R^{b} A^{b}\right)\right\}
\end{gathered}
$$

If a household switches its status and decides to purchase stocks, it must pay an entry cost of $\Gamma$. There is no lag so that the household can instantaneously trade in the stock market. The value from participating is given by:

$$
w_{t}^{p}(\Omega)=\max _{A^{b^{\prime}} \geq \underline{A}^{b}, A^{s^{\prime}} \geq 0}\left\{(1-\beta) c^{1-1 / \theta}+\beta\left[\left(1-\nu_{t+1}\right)\left(E_{t} v_{t+1}\left(\Omega^{\prime}\right)^{1-\gamma}\right)^{\frac{1}{1-\gamma}}+\nu_{t+1}\left(E_{t} B\left(A^{\prime}\right)^{1-\gamma}\right)^{\frac{1}{1-\gamma}}\right]^{1-1 / \theta}\right\}^{\frac{1}{1-1 / \theta}}(9)
$$

subject to the following constraints:

$$
\begin{gathered}
c=y+T R+R^{b} A^{b}-A^{b \prime}-A^{s \prime}-\Gamma \\
A^{\prime}=R^{b} A^{b^{\prime}}+R^{s^{\prime}} A^{s^{\prime}} \\
T R=\max \left\{0, \underline{c}-\left(y+R^{b} A^{b}\right)\right\} .
\end{gathered}
$$

It is noteworthy that the future value in equation $(9)$ is denoted by $v_{t+1}\left(\Omega^{\prime}\right)$ which is the value function of stock market participants given the future state $\Omega^{\prime}$.

\section{Quantitative Approach}

There are two stages in the estimation. First, income and return processes, by country, are estimated directly from micro data. These processes are used as inputs to solve the household optimization problem so that conditional expectations of exogenous variables are consistent with the data.

Second, the parameters, $\Theta \equiv\left(\beta_{i}, \gamma, \Gamma, F, L, \phi, \underline{c}, \theta, \underline{A}^{b}\right)$ which characterize households in a country are estimated via simulated method of moments. The discount factor, $\beta_{i}$, is indexed by education attainment, $i=0,1$, for no college and college respectively. ${ }^{13}$ The vector $\Theta$ is chosen to solve:

\footnotetext{
${ }^{13}$ From Cooper and Zhu (2015) differences in discounting across education groups are important in explaining financial choices.
} 


$$
£=\min _{\Theta}\left(M^{s}(\Theta)-M^{d}\right) W\left(M^{s}(\Theta)-M^{d}\right)^{\prime} .
$$

Here $W$ is a diagonal weighting matrix calculated as the inverse of the variances of the moments taken from Table 17. The simulated moments, $M^{s}(\Theta)$, are calculated from a simulated data set created by solving the household optimization problem. For each country, the initial distribution of asset holdings, needed as an input into the computation of moments, is taken from the data.

\subsection{Income Process}

We estimate household income processes using the European Community Household Panel (ECHP) during the period of 1994-2001 (8 waves). The ECHP is a panel survey collecting internationally comparable data on income and demographics of a representative sample of households year after year in several euro area countries. ${ }^{14}$ Our income measure is defined as total reported after-tax, non-asset household income. This definition includes labor income received by the household head and all other members of the household, such as income from work (wages, salaries and self-employment earnings) and social cash transfers (government transfers, workers compensation, unemployment insurance and old-age pensions), net of any taxes and social contributions paid. We use a broad definition of labor income to allow for insurance mechanisms other than asset accumulation within each country, such as unemployment benefits and other welfare programs present in the European countries we consider. Including only labor income would overstate the variability in income that households face while including also financial asset and capital income would understate the risk coming from earnings. ${ }^{15}$ Income from the ECHP relates to the year immediately preceding the survey (e.g. 2000 for wave 8 conducted in 2001), whereas the household composition and the sociodemographic characteristics of household members are those registered at the moment of the interview. To ensure international comparability, income data are PPP-adjusted. ${ }^{16}$

\subsubsection{Profiles}

As the slope of the deterministic income profiles and the risk properties of labor income differ by education, we split households in each country into a subsample of households whose head has a college degree and a subsample of households with a head without college degree. ${ }^{17}$ For each education group and country, data from various years are pooled together. We then regress log income on household characteristics, an age polynomial of order three and

\footnotetext{
${ }^{14}$ In 2001, the ECHP was discontinued, and since 2004, replaced by the EU Statistics on Income and Living Conditions (EU-SILC), an income survey. But it is not suitable for our analysis due to its limited panel dimension. Note that the exposition of the estimation of labour income processes follows closely Le Blanc and Georgarakos (2013).

${ }^{15}$ There are other important insurance mechanisms that our definition does not capture, namely: receipts in kind, transfers paid to and received from other households, negative capital income and imputed rents (i.e. the money value by not having to pay full market rent by living in one's own accommodation) The latter could be meaningful in particular in the Southern European countries where home ownership rates are high.

${ }^{16}$ We exclude all households whose heads are younger than 20 years of age, that report annual income smaller than zero euro, that have any crucial variable missing or who have not participated for at least two years in the survey.

${ }^{17}$ Ideally, one would define smaller education groups depending on number of years in schooling (see e.g. Cooper and Zhu (2015), Laibson, Repetto, and Tobacman (2001)) or differentiate by highest degree obtained (no high school, high school, college), see e.g. Cocco, Gomes, and Maenhout (2005), Hubbard, Skinner, and Zeldes (1994). Unfortunately, this would make the number of observations in some cells too small.
} 
either cohort or time effects. As age, time and birth year are perfectly correlated, we estimate age-income profiles controlling for time effects and assume that cohort effects are fixed: ${ }^{18}$

$$
\log \left(Y_{i t}\right)=\text { const. }+ \text { polynomial }\left(\text { age }_{i t}\right)+\text { HHComp }_{i t}+\text { Time }_{t} .
$$

Household composition, $\mathrm{HHComp}_{i t}$, includes the number of children in the household, the number of dependent adults, the number of heads in the household and time dummies. The ECHP population weights are used in the regression equation (11). ${ }^{19}$

Figure 1: Age-Income Profiles

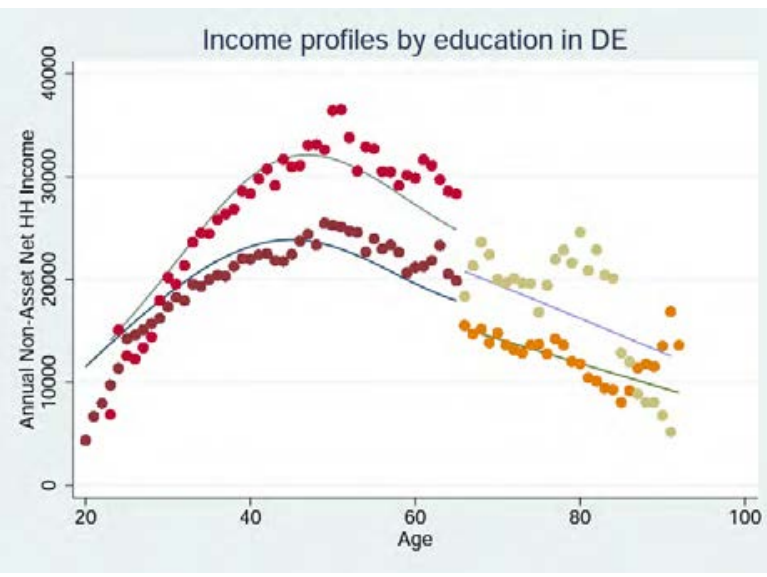

(a) Germany

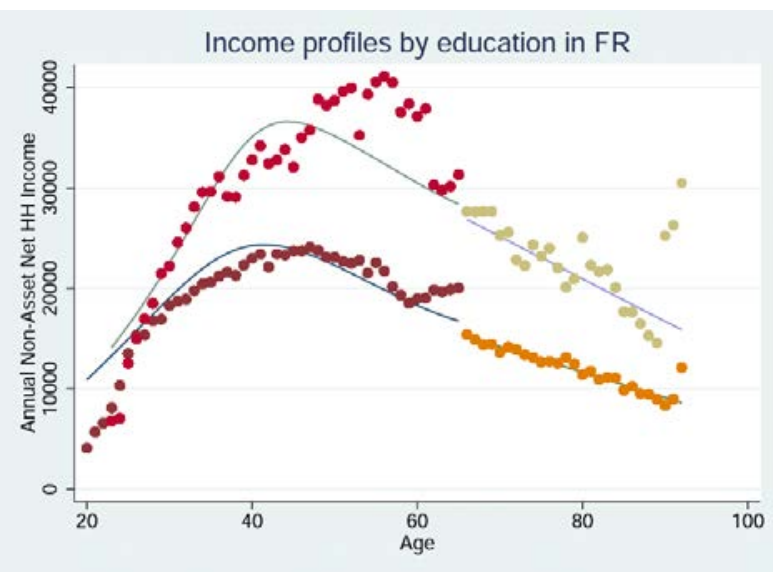

(c) France

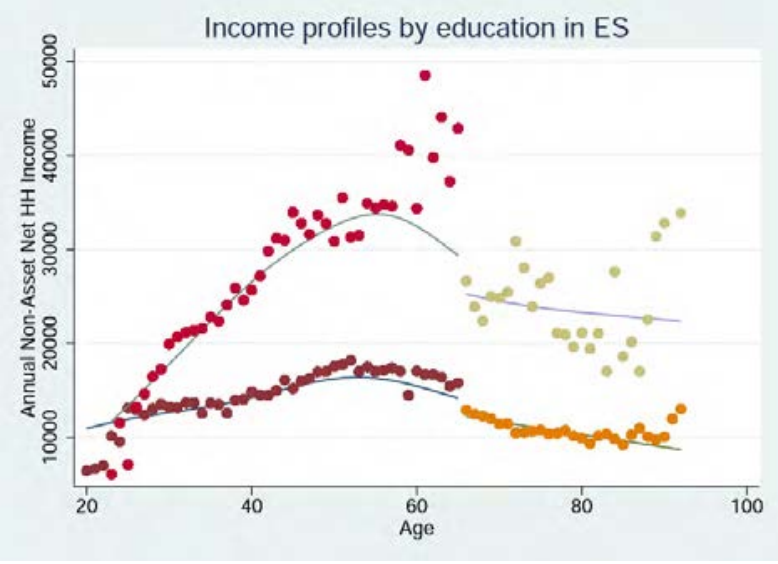

(b) Spain

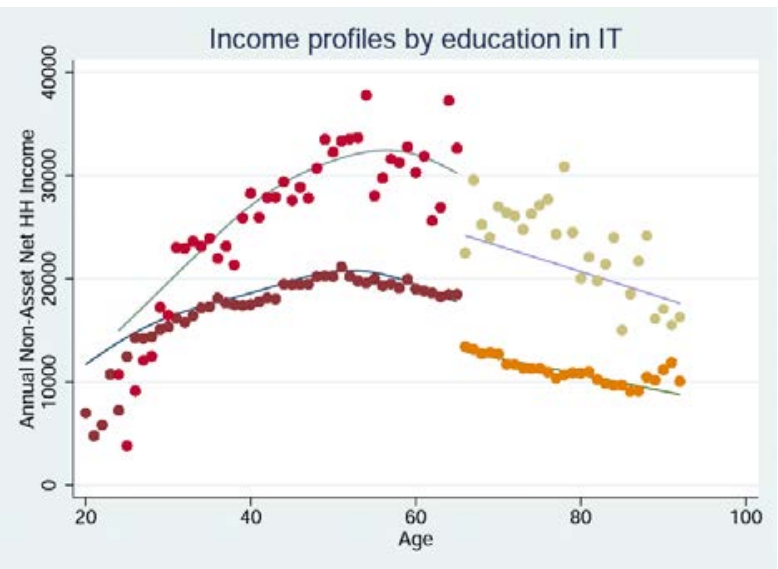

(d) Italy

The figures display fitted household income over the life-cycle for those headed by college graduates and those whose heads do not have a college degree. We fit a cubic age polynomial for our pre-retirement regression and assume a linear relation between income and age for the post-retirement period. The higher curve represents higher education households in all countries.

\footnotetext{
${ }^{18}$ We also estimated a version of the same equation including cohort instead of time effects. The shapes, levels and growth rates of these estimations are very similar to our profiles. We therefore conclude that our specification is robust to using cohort or time effects.

${ }^{19}$ Unweighted results are essentially the same.
} 
For each country and education group, we estimate this equation twice, once for households in the labor force and once for households above age 65. We assume for now that retirement takes place exogenously at age 65 , the statutory retirement age in all countries, which makes the profiles comparable over all ages. To obtain smoothed age-income profiles suitable as ingredients into the model, we fit a cubic age polynomial for our pre-retirement regression and assume that income is linear in age for the post-retirement period. ${ }^{20}$

The resulting profiles illustrate age and education-specific variations in expected income over the life-cycle for a household that has a typical life-cycle evolution in household size and has a typical time effect. ${ }^{21}$

Figure 1 displays the fitted (exponentiated) values of the income predictions for each education group and each country. The dots around the lines in Figure 1 represent the means of observed household income by age, suggesting that we fit the data reasonably well.

The resulting age-income profiles display heterogeneity with respect to both the steepness and peaks of the income profiles. After a sharp increase in the beginning of working life, income for college graduates peaks in mid-working life in Germany and France. Households whose heads are without a college degree present relatively flat profiles at a lower level than college graduates, reflecting the college premium. In the two southern countries income of college graduates grows slowly until it reaches a peak late in working life, around age 55 to 60 when the income of households within the same education group already decreases in Germany and France. Households without a college degree in Italy and Spain have on average an even flatter income profile that hardly grows over the life-cycle. The gap between employment income and retirement income varies across countries, reflecting the different generosity of the pension systems and other transfers after retirement. In particular, in Italy and Spain, reaching retirement age is connected to a large loss in income.

\subsubsection{Stochastic Components}

We use the variation in log income residuals from our estimation of the country- and education-specific income profiles from equation (11) to characterize the uncertainty of earnings over the life-cycle. Following Carroll (1992), Guvenen (2009), Laibson, Repetto, and Tobacman (2001), among others, we assume that the log income residuals, $\tilde{y}_{i, t}$, reflect income shocks and follow the stochastic process given by:

$$
\begin{gathered}
\tilde{y}_{i, t}=z_{i, t}+\epsilon_{i, t} \\
z_{i, t}=\rho z_{i, t-1}+\eta_{i, t}
\end{gathered}
$$

where $\epsilon_{i, t}$ and $\eta_{i, t}$ are independent zero-mean random shocks, with variance $\sigma_{\epsilon}^{2}$ and $\sigma_{\eta}^{2}$ respectively. The shock $\eta_{i, t}$ is persistent, with a persistence parameter of $\rho$.

The identification of the structural parameters in equation (12), i.e. $\left(\sigma_{\epsilon}^{2}, \sigma_{\eta}^{2}, \rho\right)$, is achieved by minimizing the

\footnotetext{
${ }^{20}$ Note that the retirement period is left out by most papers and many authors assume a flat income scheme after retirement, e.g. Cocco, Gomes, and Maenhout (2005). We find the resulting age-decreasing pattern more plausible.

${ }^{21}$ For details on the exact regressions and robustness checks of the income profiles see Le Blanc and Georgarakos (2013) and the literature therein.
} 
distance between the theoretical and the empirical autocovariances of the process using an iterative process that employs an optimal weighting matrix, as proposed by Hansen (1982) and Chamberlain (1984). ${ }^{22}$

Table 2: Stochastic Processes by education and country

\begin{tabular}{lllllll}
\hline \hline \multicolumn{5}{c}{ Germany } & \multicolumn{3}{c}{ Spain } \\
& $\rho$ & $\sigma_{\epsilon}^{2}$ & $\sigma_{\eta}^{2}$ & $\rho$ & $\sigma_{\epsilon}^{2}$ & $\sigma_{\eta}^{2}$ \\
\hline No college & $0.895^{* * *}$ & $0.022^{* * *}$ & $0.016^{* * *}$ & $0.951^{* * *}$ & $0.092^{* * *}$ & $0.016^{* * *}$ \\
& $(0.005)$ & $(0.001)$ & $(0.001)$ & $(0.007)$ & $(0.004)$ & $(0.002)$ \\
College & $0.937^{* * *}$ & $0.020^{* * *}$ & $0.011^{* * *}$ & $0.986^{* * *}$ & $0.058^{* * *}$ & $0.004^{* *}$ \\
& $(0.008)$ & $(0.001)$ & $(0.001)$ & $(0.007)$ & $(0.004)$ & $(0.002)$ \\
\hline \multirow{5}{*}{ No college } & $0.971^{* * *}$ & $0.031^{* * *}$ & $0.006^{*}$ & $0.944^{* * *}$ & $0.072^{* * *}$ & $0.020^{* * *}$ \\
& $(0.014)$ & $(0.006)$ & $(0.003)$ & $(0.005)$ & $(0.003)$ & $(0.002)$ \\
College & $0.941^{* * *}$ & $0.023^{* * *}$ & $0.018^{* * *}$ & $0.921^{* * *}$ & $0.029^{* * *}$ & $0.022^{* * *}$ \\
& $(0.007)$ & $(0.003)$ & $(0.002)$ & $(0.016)$ & $(0.01)$ & $(0.006)$ \\
\hline \hline
\end{tabular}

Robust standard errors in parentheses. $* * * p<0.01, * * p<0.05, * p<0.1$

The model is $\tilde{y}_{i, t}=z_{i, t}+\epsilon_{i, t} ; z_{i, t}=\rho z_{i, t-1}+\eta_{i, t}$ where $\tilde{y}_{i, t}$ is the logarithm of after-tax, after unemployment benefits, non-capital income of the household head and spouse (if present), net of the predictable part of income. The regression includes year dummies. The error structure is estimated by optimally weighted GMM, minimizing the distance between the theoretical and the empirical first six autocovariances (including the autocovariance of lag 0 , i.e. the cross-sectional variance). The reported variances are pooled over the sample period and over cohorts.

Table 2 displays the estimates of the variances of the persistent and transitory shocks and the persistence parameter by education level for each country. Over the whole sample, households in Germany face the lowest persistence of income shocks $(\rho=0.91)$ while Italian and French households have highly persistent shocks $(\rho=0.98$ and 0.96 respectively). Permanent shocks to income are lower for college graduates than for non-college educated households. This is consistent with the notion that shocks to more educated households are small but they could be very persistent as their human capital is more specific. Also, the transitory component of income is usually lower for households with a college degree (with the exception of France). College graduates in Germany display low permanent and transitory shocks. In Italy and Spain, lower educated households face large and very persistent permanent shocks. ${ }^{23}$

\footnotetext{
${ }^{22}$ In particular, we use a Generalized Method of Moments (GMM) estimator to minimize the distance between the theoretical and empirical autocovariances which has the advantage of requiring strong distributional assumptions while still achieving asymptotic efficiency. For details about moments construction and the estimation method, see Le Blanc and Georgarakos (2013) and Guvenen (2009).

${ }^{23} \mathrm{On}$ interpretation of this result is that the economic expansion that started roughly 10 years before the first wave of our data set (in particular in Spain but also in Italy) mostly benefited the more educated while permanent income uncertainty increased for the less educated.
} 


\subsection{Asset Returns}

The real return on bonds is non-stochastic and is set at $2 \%$ for all countries. The real return on stock investment, including both dividends and capital gains, is assumed to be i.i.d. at the annual frequency, with the return shocks normally distributed. The mean and standard deviation of stock return shocks for each country are given by the following table.

Table 3: Stock Return Processes

\begin{tabular}{lcc}
\hline \hline & mean & standard deviation \\
\hline Germany & 0.102 & 0.262 \\
Spain & 0.077 & 0.251 \\
France & 0.091 & 0.246 \\
Italy & 0.065 & 0.276 \\
\hline
\end{tabular}

This table reports the mean and standard deviation of real stock return by country between 1951-2012.

The annual mean return ranges from a low of $6.4 \%$ in Italy to $10.2 \%$ in France. The standard deviation is about the same across countries. To be clear, these are returns by country not by household residing in a country. Given the amount of home bias existing in these households' portfolios, this distinction is not very important. ${ }^{24}$

\subsection{Moments}

The moments for the structural estimation are shown in the left panel of Table $4 .^{25}$ The moments come from country-specific regressions of a particular household financial variable on a constant, age, age-squared, a dummy for better education that is set to one for college graduates, and home equity and home ownership status to control for housing which is outside the structural model. Thus the moments used for the estimation go beyond the summary moments presented in Table 1 by allowing the dependence of financial decisions on age and educational attainment, controlling for home ownership.

A couple of points stand out. Education matters for households' financial decisions. It has a significant positive association with participation and a negative association with stock share in all countries. Further, both participation and the stock share exhibit a significant hump-shape in all countries. Finally, the wealth-income ratio is increasing with age in all four countries. The shape is convex in Germany and France and concave in Spain and Italy. An increase in education increases the wealth income ratio in all countries except Italy. For Italy, the wealth income ratio falls with education up to age 55 .

To illustrate the life-cycle aspects of these moments, Figure 2 shows the age-profile of these moments for Germany for the two education groups. There are slight hump-shapes in participation and the stock share. And both are well below $100 \%$. The wealth income ratio is increasing in age for both education groups.

\footnotetext{
${ }^{24}$ That said, an extension of the model that distinguishes between participation in home vs foreign markets could be of interest in smaller very open economies. Unfortunately, the participation measure in the HFCS data does not distinguish between home and foreign markets.

${ }^{25}$ The standard errors are reported in Table 17.
} 
Table 4: Data and Model Moments

\begin{tabular}{|c|c|c|c|c|c|c|c|c|c|c|}
\hline & con. & age & $a g e^{2}$ & $\begin{array}{c}\text { college } \\
(* \text { age })\end{array}$ & $\begin{array}{c}\text { college } \\
* \text { age }^{2}\end{array}$ & con. & age & $a g e^{2}$ & $\begin{array}{c}\text { college } \\
(* \text { age })\end{array}$ & $\begin{array}{c}\text { college } \\
* \text { age }^{2}\end{array}$ \\
\hline & \multicolumn{5}{|c|}{ Germany: Data } & \multicolumn{5}{|c|}{ Germany: Model } \\
\hline Part. & 0.250 & 0.018 & -0.00026 & 0.159 & & -0.314 & 0.033 & -0.00023 & 0.105 & \\
\hline Share & 0.004 & 0.023 & -0.00024 & -0.060 & & 0.020 & 0.024 & -0.00023 & -0.060 & \\
\hline \multirow[t]{2}{*}{$\mathrm{W} / \mathrm{I}$} & 0.542 & -0.008 & 0.00022 & 0.037 & -0.00036 & 1.082 & -0.030 & 0.00036 & -0.028 & 0.00061 \\
\hline & \multicolumn{5}{|c|}{ Spain: Data } & \multicolumn{5}{|c|}{ Spain: Model } \\
\hline Part. & -0.716 & 0.035 & -0.00034 & 0.161 & & -0.489 & 0.039 & -0.00032 & 0.251 & \\
\hline Share & -0.116 & 0.027 & -0.00025 & -0.049 & & -0.094 & 0.027 & -0.00024 & -0.044 & \\
\hline \multirow[t]{2}{*}{$\mathrm{W} / \mathrm{I}$} & -1.675 & 0.065 & -0.00036 & 0.013 & 0.00012 & 0.824 & -0.007 & 0.00003 & -0.059 & 0.00131 \\
\hline & \multicolumn{5}{|c|}{ France: Data } & \multicolumn{5}{|c|}{ France: Model } \\
\hline Part. & -0.090 & 0.015 & -0.00013 & 0.148 & & -0.173 & 0.030 & -0.00025 & 0.222 & \\
\hline Share & 0.056 & 0.013 & -0.00007 & -0.017 & & 0.048 & 0.010 & -0.00008 & -0.019 & \\
\hline \multirow[t]{2}{*}{$\mathrm{W} / \mathrm{I}$} & 1.344 & -0.050 & 0.00070 & -0.004 & 0.00030 & 0.805 & -0.018 & 0.00031 & -0.074 & 0.00234 \\
\hline & \multicolumn{5}{|c|}{ Italy: Data } & \multicolumn{5}{|c|}{ Italy: Model } \\
\hline Part. & -0.117 & 0.014 & -0.00017 & 0.089 & & -0.188 & 0.027 & -0.00019 & 0.171 & \\
\hline Share & 0.225 & 0.015 & -0.00016 & -0.082 & & 0.284 & 0.015 & -0.00017 & -0.078 & \\
\hline $\mathrm{W} / \mathrm{I}$ & -0.062 & 0.023 & -0.00018 & -0.023 & 0.00042 & 0.268 & 0.010 & -0.00005 & -0.050 & 0.00125 \\
\hline
\end{tabular}

This table reports data and model moments. For the wealth-income ratio regression, the regressors include a constant, age, age-squared, college*age, college*age-squared. For all regressions, controls included home equity and home ownership status.

Figure 2: Graphical Presentation for Household Finance Moments in the Data (Germany)
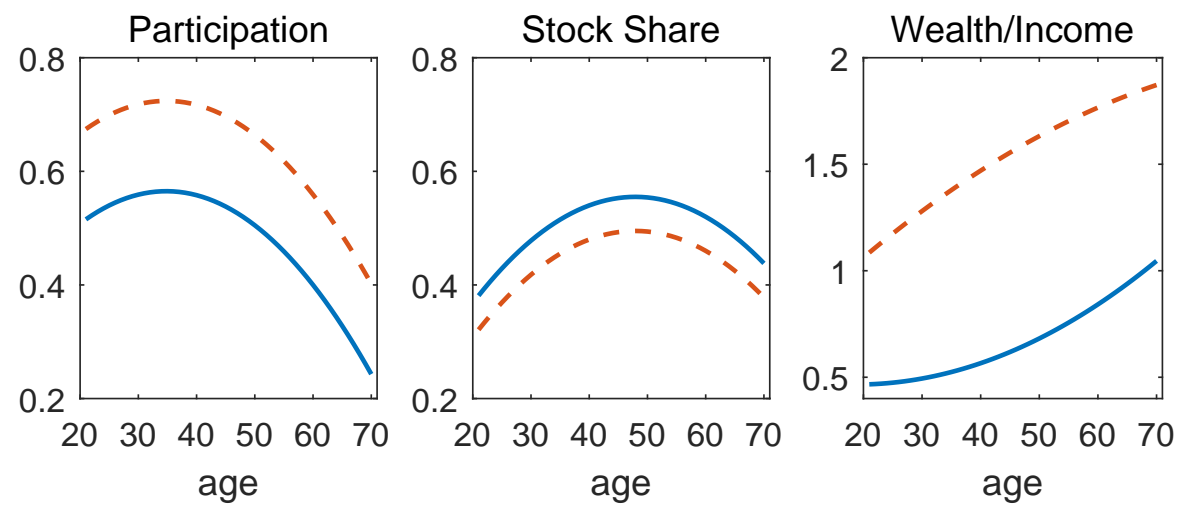

This figure shows the average profiles of stock market participation, stock share in wealth and the wealth to income ratio by education for Germany. The high education group is indicated by the broken curves and the low education group by the solid curves.

The regressions control for home ownership status and home equity. Table 5 summarizes the findings on the effects of home ownership on household financial moments: these are the regression coefficients for the home ownership dummy. For all countries, home ownership is complementary to asset market participation, particularly in Italy and France. Though not reported in the table, this is true for home equity as well. The correlation of home ownership and the shock share is negative for Germany and France, but positive for Spain Italy. The correlation with the financial wealth to income ratio is negative, except for Germany. These are interesting moments that make clear the importance of conditioning on home ownership and housing wealth in the calculation of the moments we 
Table 5: Housing Impact on Household Financial Choices

\begin{tabular}{c|ccc}
\hline \hline Country & participation & share & wealth income ratio \\
\hline Germany & 0.071 & -0.043 & 0.425 \\
Spain & 0.051 & 0.033 & -0.259 \\
France & 0.103 & -0.043 & -0.269 \\
Italy & 0.081 & 0.033 & -0.218 \\
\hline \hline
\end{tabular}

$\overline{\text { This table summarizes the effects of the home ownership on financial }}$ choices (i.e. the coefficient of the home ownership dummy) by country. These estimates are all significantly different from zero at the $5 \%$ significance level.

match.

To be clear, the moments in Table 4 summarize patterns in the data. Understanding the features of preferences and the shocks that drive these patterns will come through the estimation of the household dynamic optimization model.

\section{Results}

The moments from the estimated model are reported in the right panel of Table 4 and the parameter estimates appear in Table 6. The latter table includes a goodness of fit measure, computed using (10).

\subsection{Preference Parameters}

As Cooper and Zhu (2015) found for the US, the discount factor is considerably lower than the conventional value of 0.95 but in line with models of buffer stock saving like Deaton (1991). It averages about 0.79 for the low education group, and it increases with educational attainment. The estimates range from 0.848 in Germany to 0.895 in Italy for the high education group. An important role for the discount factor is to limit the accumulation of savings to match the wealth income ratio that differs by educational attainment, given the high mean returns on stocks relative to bonds. Our estimates are in line with those of Fagereng, Gottlieb, and Guiso (2017), who use Norwegian tax data to estimate a discount factor in the range from 0.77 to 0.82 . The authors argue that impatience is necessary to limit liquid asset accumulation and discourage stock market participation in the presence of participation and adjustment costs. Calvet, Campbell, Gomes, and Sodini (2016) use household-level administrative data from Sweden in a lifecycle model with Epstein-Zin-Weil preferences. They estimate the discount factor to be 0.993 when they include real estate as risky investment which makes the risky share of households considerably higher, and drops to 0.923 when they exclude it. Their model, unlike ours, abstracts from a bequest motive and fixed participation costs needed to match the life-cycle savings and portfolio choices.

These findings also contrast with the estimates reported in Carroll, Slacalek, and Tokuoka (2014) who allow heterogeneity in discount factors across households and estimate the distribution of discount factors around 0.97 with a relatively small variation across households. In their paper, the estimates are obtained by matching moments 
Table 6: Parameter Estimates

\begin{tabular}{lccccccccccc}
\hline \hline & $\beta_{0}$ & $\beta_{1}$ & $\gamma$ & $\Gamma$ & $F$ & $L$ & $\phi$ & $\underline{c}$ & $\theta$ & $\underline{A}^{b}$ & Fit \\
\hline Germany & 0.822 & 0.848 & 17.638 & 0.014 & 0.011 & 0.030 & 0.103 & 0.290 & 0.509 & -0.072 & 1343 \\
& $(0.007)$ & $(0.009)$ & $(4.134)$ & $(0.008)$ & $(0.024)$ & $(0.028)$ & $(0.862)$ & $(0.233)$ & $(0.038)$ & $(1.266)$ & \\
Spain & 0.779 & 0.860 & 10.275 & 0.010 & 0.011 & 0.054 & 0.425 & 0.299 & 0.357 & -0.062 & 688 \\
& $(0.019)$ & $(0.026)$ & $(0.496)$ & $(0.002)$ & $(0.003)$ & $(0.048)$ & $(0.603)$ & $(0.014)$ & $(0.03)$ & $(0.391)$ & \\
\multirow{2}{*}{ France } & 0.752 & 0.867 & 21.308 & 0.008 & 0.017 & 0.060 & 0.589 & 0.134 & 0.373 & -0.088 & 7174 \\
& $(0.009)$ & $(0.004)$ & $(0.237)$ & $(0.001)$ & $(0.001)$ & $(0.002)$ & $(0.119)$ & $(1.337)$ & $(0.018)$ & $(0.962)$ & \\
Italy & 0.823 & 0.895 & 8.255 & 0.011 & 0.006 & 0.100 & 0.823 & 0.329 & 0.436 & -0.085 & 716 \\
& $(0.01)$ & $(0.002)$ & $(0.455)$ & $(0.003)$ & $(0.002)$ & $(0.026)$ & $(0.859)$ & $(0.063)$ & $(0.126)$ & $(0.123)$ & \\
\hline \hline
\end{tabular}

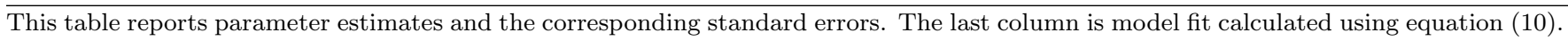

of the liquid asset holdings distribution of households.

The estimated risk aversion, ranging from 8.255 in Italy to 21.308 in France, is considerably higher than the estimated value of around 4 for the US reported in Cooper and Zhu (2015). This is not surprising given the small participation rates in the stock market in our sample countries compared with the US. Increases in risk aversion reduce both participation and stock share in the portfolio. In addition, Cooper and Zhu (2015) abstracts from borrowing, which reduces risky investment without imposing higher risk aversion of households.

Our estimates are consistent with other estimates for Europe. Fagereng, Gottlieb, and Guiso (2017) estimate a risk aversion parameter of 11 to 14 depending on whether they allow for a small disaster probability and a bequest motive. Calvet, Campbell, Gomes, and Sodini (2016) estimate the average relative risk aversion parameter to be 4.15 when they include real estate as a risky investment and 10.9 when they do not.

The elasticity of intertemporal substitution, $\theta$, is also statistically significant in all countries. It is far from the inverse of the risk aversion estimate, thus inconsistent with the CRRA model.

As emphasized later, the distinction between risk aversion and intertemporal substitution through the EZW preference specification is quite important for understanding the response of households to variations in income and stock returns induced by monetary policy. The identification of these parameters is discussed in sub-section 5.2 .

Other studies have used information from direct or indirect questions on risk and time preferences from surveys to infer risk aversion parameters (see, for example, Guiso and Paiella (2006), Guiso and Paiella (2008), Bonin, Dohmen, Falk, Huffman, and Sunde (2007)). Making use of a question on households' willingness to pay for a hypothetical risky security in the 1995 Bank of Italy Survey of Household Income and Wealth (SHIW), Guiso and Paiella (2006) and Guiso and Paiella (2008) infer a relative risk aversion measure of 6 which ranges from 1.9 to 13.3 in the data.

The stock market participation cost, $\Gamma$, and portfolio adjustment cost, $F$, are given as fractions of average income in a country. The participation cost of $1.4 \%$ of permanent income in Germany is the highest among the four countries, and the cost is relatively low in France. The adjustment costs are relatively high in France and Spain, while for Italy the adjustment cost is relatively small, though statistically significant. These variations in 
participation and adjustment costs influence the life-cycle patterns of participation. The adjustment costs also directly impact the stock share since they generate a demand for liquidity through bond holdings.

The point estimates of $L$ indicate a bequest motive and are statistically significant in France and Italy. Further, there is a positive point estimate of $\phi$, the luxuriousness of bequest, in all four countries but these are only significantly different from zero in France.

The consumption floor, $\underline{c}$, is estimated relative to a country's average income. For Spain and Italy $\underline{c}$ is around $30 \%$ and is precisely estimated. The point estimate for the floor is also high in Germany but it is not statistically significant there, nor in France.

The model estimates a borrowing constraint. The point estimates are negative for each country, indicating that some borrowing is feasible. But these estimates are not precise, and not statistically different from zero.

However, as will become clear in the remainder of the text the frequency of households actually being bound by the borrowing constraint is essentially zero. ${ }^{26}$ Of course, this does not mean that the borrowing constraint does not influence behavior. As indicated in Table 8, variations in the borrowing limit influence moments. In particular, an increase in $\underline{A}^{b}$ increases the share of risky assets in the portfolio and increases the wealth to income ratio, while reducing the participation rate. Intuitively, if households are less able to borrow, then they will save more as a buffer. To the extent they do so by holding bonds, this will reduce the participation rate.

Table 7: Participation and Adjustment Rates

\begin{tabular}{cc|ccc|ccc|c}
\hline \hline Country & \multirow{2}{*}{ Inc } & \multicolumn{3}{|c|}{ Participation Rate } & \multicolumn{3}{|c|}{ Adjustment Rate } & Fraction of HHs \\
& low & low & middle & high & low & middle & high & hitting $\underline{c}$ \\
\hline \multirow{2}{*}{ Germany } & low & 0.161 & 0.853 & 0.984 & 0.302 & 0.193 & 0.219 & 0.057 \\
& high & 0.542 & 0.913 & 0.995 & 0.279 & 0.244 & 0.309 & 0.000 \\
\multirow{3}{*}{ France } & low & 0.143 & 0.668 & 0.912 & 0.170 & 0.134 & 0.219 & 0.106 \\
& high & 0.646 & 0.899 & 0.998 & 0.178 & 0.295 & 0.440 & 0.001 \\
\multirow{2}{*}{ Italy } & low & 0.101 & 0.741 & 0.913 & 0.002 & 0.008 & 0.072 & 0.000 \\
& high & 0.645 & 0.981 & 1.000 & 0.132 & 0.324 & 0.579 & 0.000 \\
& low & 0.142 & 0.776 & 0.988 & 0.229 & 0.195 & 0.317 & 0.092 \\
\hline \hline
\end{tabular}

This table summarizes stock market participation rates and adjustment rates by education and permanent income, and the fraction of household hitting the consumption floor for each education group. All the numbers are calculated from simulated data.

Other implications from these estimates are shown in Table 7. The table reports the average participation rates, the adjustment rates conditional on participation and the fraction of households hitting the consumption floor, by country and by permanent income realization. The participation rates are increasing in income and education, and are nearly $100 \%$ for the richest, highly educated households. The adjustment rates, obtained by simulation, are much lower than those found in US data. In comparison to these findings, Cooper and Zhu (2015) report an average adjustment rate of about $60 \%$ for US households.

\footnotetext{
${ }^{26}$ This is reminiscent of Krusell and Smith (1998) where the presence of a borrowing constraint does not create a nonlinearity as relatively few households are bound by the constraint.
} 


\subsection{Local Identification}

Another perspective on the link between parameters and moments is given in Table 8. The table shows the elasticity of the model moments, i.e., coefficients in the participation, share, and wealth to income ratio regressions, with respect to a small variation in the structural parameters, one at a time. A large elasticity indicates that a moment is important in identifying a particular parameter. These elasticities are informative about local identification as the variations in parameters are in the neighborhood of the estimated values. This table provides information about local identification for a single country, Spain.

The local changes in discount factors exhibit large effects on simulated moments, leading to the precise estimates for both parameters. An increase in $\beta_{0}$ leads to more savings and hence higher wealth to income ratios for the less educated group. As reflected in the negative elasticities on the coefficients of age $* e d u$ and $a g e^{2} * e d u$ in the wealth to income ratio regression, an increase in $\beta_{0}$ also leads to a smaller education gap in terms of the wealth to income ratio. Also for $\beta_{0}$, the elasticity is negative for the coefficients on the education dummy in the participation regression, which indicates a reduced education gap in terms of stock market participation. The negative elasticity for the constant term in the participation regression reflects earlier participation of the less educated group. ${ }^{27}$ Similarly, an increase in $\beta_{1}$ widens the education gap in terms of stock market participation rates and wealth income ratios, which is evident in the second row of the table.

An increase in the coefficient of relative risk aversion, $\gamma$, decreases stock market participation and the stock share in wealth, conditional on participation. The signs are exactly what is expected and it is clear that this response is key to the identification of $\gamma$. The effect of $\gamma$ on wealth accumulation is less straightforward. On the one hand, a higher $\gamma$ leads to a safer portfolio that generates lower return and hence less wealth accumulation. On the other hand, a higher $\gamma$ implies the lower certainty equivalent future value due to Jensen's inequality, which leads to more wealth accumulation. Table 8 indicates that the first effect is more important around the point estimate of $\gamma$, especially for the less educated households.

Variations in the inter-temporal elasticity of substitution, $\theta$, also have substantial effects on the wealth to income ratio. A higher $\theta$ implies a higher degree of inter-temporal substitution and the lower preference for consumption smoothing over time, which leads to less wealth accumulation.

The participation cost, $\Gamma$, has a negative effect on stock market participation. Consequently, the participants are wealthier due to the selection effect, thus they have a higher stock share in total wealth on average. The participation cost also widens the gap in participation rates between the two education groups, as indicated by the positive coefficient on education dummy. This is because the more educated households care less about the participation cost which is small relative to their income and wealth.

The stock market adjustment cost, $F$, has a negative effect on both the stock market participation rate and stock share. It also widens the gap in stock shares between the two education groups.

\footnotetext{
${ }^{27}$ This is confirmed when we compare the participation profiles before and after the local changes in $\beta_{0}$. The comparison shows that the the less educated group leave the stock market earlier given the higher $\beta_{0}$. This is because the higher $\beta_{0}$ causes some low income households to enter the stock market when they are young, and they exit early after retirement as they rely on the consumption floor toward the later stage of life.
} 
Table 8: Elasticity of Moments to Parameter Values (Spain)

\begin{tabular}{c|cccc|cccc|ccccc}
\hline \hline & \multicolumn{4}{|c|}{ Participation } & \multicolumn{4}{c|}{ Share } & \multicolumn{4}{c}{ Wealth-to-income Ratio } \\
& con & age & age & $\begin{array}{c}\text { edu } \\
\text { high })\end{array}$ & con & age & age & $\begin{array}{c}\text { edu } \\
\text { high })\end{array}$ & con & age & age & $\begin{array}{c}\text { age } \\
\text { edu }\end{array}$ & $\begin{array}{c}\text { age } \\
\text { edu }\end{array}$ \\
\hline$\beta_{0}$ & -3.765 & -0.799 & -2.396 & -10.70 & -37.47 & -4.938 & -5.383 & 10.40 & 10.84 & 68.17 & 217 & -2.406 & -3.313 \\
$\beta_{1}$ & 2.135 & 1.371 & 1.771 & 2.723 & -83.99 & -8.185 & -5.502 & 2.891 & 19.34 & 85.89 & 156 & 14.30 & 16.45 \\
$\gamma$ & -153 & -67.5 & -65.7 & 25.67 & -79.76 & -11.40 & -11.46 & 6.599 & -5.439 & -27.83 & -52.422 & 0.515 & 0.415 \\
$\Gamma$ & -0.272 & -0.293 & -0.377 & 0.159 & 3.042 & 0.157 & 0.053 & -2.034 & -0.015 & -0.051 & 0.000 & -0.005 & -0.002 \\
$F$ & -0.253 & -0.170 & -0.190 & 0.043 & 0.075 & -0.195 & -0.314 & 1.513 & 0.156 & 0.850 & 1.816 & -0.017 & -0.017 \\
$L$ & 0.016 & 0.006 & 0.002 & -0.020 & 1.606 & 0.265 & 0.302 & 0.005 & 1.662 & 7.930 & 15.36 & 0.417 & 0.409 \\
$\phi$ & -0.003 & 0.000 & 0.005 & 0.007 & -0.286 & -0.077 & -0.108 & -0.341 & -0.230 & -1.129 & -2.336 & -0.050 & -0.051 \\
$c$ & -154 & -68.62 & -67.02 & 27.77 & -56.45 & -7.619 & -7.546 & -0.939 & -2.751 & -8.416 & -14.04 & 0.218 & 0.210 \\
$\theta$ & -0.299 & -0.514 & -0.281 & 2.448 & 0.135 & -0.291 & -0.601 & -5.144 & -3.158 & -16.03 & -42.61 & -1.494 & -1.496 \\
$A^{b}$ & -0.002 & 0.004 & 0.002 & 0.001 & 0.630 & 0.071 & 0.064 & -0.127 & 0.037 & 0.192 & 0.419 & -0.006 & -0.003 \\
\hline \hline
\end{tabular}

This table reports the elasticity of moments with respect to parameter values, one at a time, at the baseline estimations for Spain.

A larger consumption floor lowers the precautionary saving motives, thus has a significantly negative effect on wealth accumulation, especially for the less educated households who rely more on the consumption floor. With the much reduced wealth, it is less attractive for less educated households to participate in the stock market or rebalance the portfolio, which lowers their stock market participation rate and stock share in wealth.

\section{MPC Distributions}

This section studies the distribution of the marginal propensity to consume (MPC) across households by country in response to shocks to income and stock returns. The MPC is the natural summary statistic for a household response to a shock, thus the distribution of MPC matters in determining the impact of monetary policy on aggregate consumption through the income and return channels.

Heterogeneity in the consumption response of households to variations in income and stock returns is a natural consequence of our model. The responses to shocks tend to be nonlinear, due to the discrete choices by households and the non-homothetic feature of household preferences introduced through the consumption floor and luxuriousness of bequest. Further, the evolution of the cross sectional distribution across households can generate endogenous persistence. Of course, all of these features may themselves differ across countries.

In particular, the frictions in asset market participation and adjustment matter for the response of households to shocks. As emphasized in Bonaparte, Cooper, and Zhu (2012), the non-convex portfolio adjustment cost implies a non-linear response to income and interest rate variations. Further, borrowing constraints can bind, even for apparently wealthy households due to liquidity shortages, as suggested by Kaplan and Violante (2014). This has policy implications as shown by the recent work of Kaplan, Violante, and Weidner (2014), Kaplan and Violante (2014) and Kaplan, Moll, and Violante (2018).

Beside the discrete choices and the binding borrowing constraint, it is important to note that the consumption floor $\underline{c}$ is much more relevant for low income households than high income households, which also leads to hetero- 
geneity in MPCs. This is related to the discussion in Kaplan and Violante (2014) since households relying on the consumption floor are more likely to be hand-to-mouth households and thus have high marginal propensities to consume. We will characterize these households both in actual and simulated data.

In addition, the parameter $\phi$ in our model captures the degree of luxuriousness of bequest. For households with low income, it is optimal to run down their wealth as their death probability rises with age. But for high income or high wealth level households, the optimal decision rule is to keep the high level of wealth as bequests. This non-homotheticity in preferences further leads to heterogeneity in MPCs.

Other studies on life-cycle portfolio choice and MPCs include Cocco, Gomes, and Maenhout (2005) and Gomes and Michaelides (2005) where older unconstrained households have higher MPC to transitory income (or wealth) shocks, since they consume those gains over a shorter period of time and they face significantly less uncertainty about their lifetime income and wealth. We also fit a realistically calibrated income process to our model and calculate MPCs out of transitory income shocks.

Jappelli and Pistaferri (2014) study MPC heterogeneity of Italian households. They find that households with low cash-on-hand exhibit a much higher MPC than affluent households, which is in agreement with models with precautionary savings where income risk plays an important role. They find that a debt-financed increase in transfers of 1 percent of national disposable income targeted to the bottom decile of the cash-on-hand distribution would increase aggregate consumption by 0.82 percent.

Christelis, Georgarakos, Jappelli, Pistaferri, and van Rooij (2018) use a representative survey of the Dutch population to characterize empirically the distribution of the MPC in response to small and large as well as positive and negative unexpected transitory income changes and compare the findings with several predictions of intertemporal consumption models. They find that the average MPC is in the 15-25\% range. Also, the consumption response to income shocks declines with economic resources, it is larger for negative income shocks and smaller if consumers have relatively long horizons.

Here we focus on the MPC distribution from (positive) transitory income and return shocks. Our methodology is quite different from existing studies. We do not rely on auxiliary regressions. Instead, we simulate income and return variations and determine the response using the country-specific estimated decision rules.

To return to the issue of housing, one concern is that by taking housing out of the moments and the model, our MPC estimates are biased. The literature does not fully inform us on this issue. Garbinti, Lamarche, Lecanu, and Savignac (2020) estimate the MPC out of financial and housing wealth. For two countries, Spain and Italy, they find that the MPC out of financial wealth is much larger than it is from variations in housing wealth. The opposite is true for Germany, where they see a small response of consumption to financial wealth. Cloyne, Ferreira, and Surico (2020) identify a housing-specific channel of monetary policy as those with housing debt (mortgagors) respond more to monetary policy than outright homeowners, but the income effects of monetary policy are about the same regardless of indebtedness and homeowner status, implying higher MPCs of mortgagors. Hintermaier and Koeniger (2018) conduct an interest rate experiment in a calibrated model and find a large response through refinancing. The return channel that we study focuses on the stock market response to monetary policy, which 
Table 9: Household Distribution by Income and Education

\begin{tabular}{cc|ccc}
\hline \hline \multirow{2}{*}{ Country } & Inc & low & middle & high \\
& Ed & & & \\
\hline \multirow{2}{*}{ Germany } & low & 0.146 & 0.292 & 0.146 \\
& high & 0.104 & 0.208 & 0.104 \\
France & low & 0.180 & 0.361 & 0.180 \\
& high & 0.070 & 0.139 & 0.070 \\
Italy & low & 0.161 & 0.322 & 0.161 \\
& high & 0.089 & 0.178 & 0.089 \\
& low & 0.221 & 0.441 & 0.221 \\
\hline \hline
\end{tabular}

This table summarizes the distribution of households by education and permanent income for each country in the simulated data.

complements these papers that focus on housing and mortgage. It is important to note that none of the above papers provides direct evidence on the effects of home ownership on the estimated MPC in response to monetary shocks. This is not to say that the housing channel is not important: the findings in Cloyne, Ferreira, and Surico (2020) are persuasive. But there is no evidence that home ownership status or housing wealth directly impacts the income and stock return effects that are our focus.

Table 9 summarizes the distribution of households by education and permanent income within each country. ${ }^{28}$ As we proceed through the various experiments this distribution will remain fixed. For all of the countries, the largest cell is the low education middle income group.

\subsection{Income Shock}

This sub-section studies the consumption response to $1 \%$ and $10 \%$ increases in transitory income. The increase in income is given as a lump sum to all households. Thus differences in consumption responses among households are not driven by differences in the amount of the transfer. For this exercise, we simulate the consumption of each household in the baseline economy, then we impose an exogenous increase in transitory income to all households and re-simulate their consumption. For each household, the MPC is calculated as the contemporaneous change in consumption divided by the change in income.

Table 10 presents the MPC by country for each of the three levels of permanent income by education group. Within each experiment, we report the MPC for all households and for stock market participants only. The numbers reported are the mean value of the MPC for each cell.

A couple of features are apparent. First, for all countries and education groups, the MPC is highest for the low permanent income group and then falls with the level of permanent income. Second, while the low education, low permanent income group has the highest MPC in each country, the MPC of this group is much higher in Italy and Spain relative to France and Germany. For this cell, the MPC is over two-thirds in the latter two countries. From

\footnotetext{
${ }^{28}$ These are calculated based upon a simulation using the initial distribution of households in the state space from the data and then averaging over aggregate return shocks to obtain a cross sectional distribution, conditional on age.
} 
Table 10: MPC Distribution: Income Shock

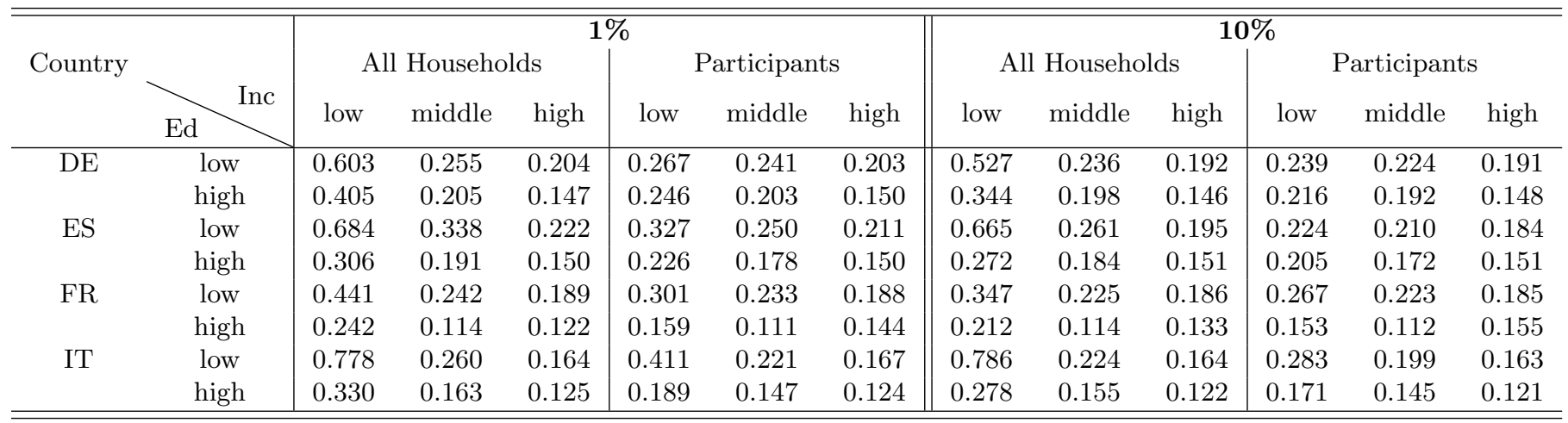

This table summarizes the distribution of MPC from transitory income shocks. The three columns (low, middle and high) represent three levels of permanent income. The rows, by country, are for low and high educational attainment for all households as well as those participating in asset markets. The left block is for a $1 \%$ transitory shock and the right is for a $10 \%$ transitory income shock.

Table 9, Spain and Italy have the largest fractions of low education, low permanent income and low education middle income households among the four countries. Thus the highest MPC group gets more weight in these two countries. The lowest MPC is associated with the high education, high permanent income group and there are relatively small differences in this cell across countries. This group is largest in France and Germany.

Third, in almost all cells, the MPC is lower for stock market participants. This is particularly clear for the low income group where participation rates are lowest. In France and Germany stock market participants have a slightly higher MPC than non-participants for the high education and high income cell. In the data as well as in the model, these high education and high income participants have a larger stock share on average. It is likely that they have a high MPC relative to non-participants because in the presence of portfolio adjustment costs, some of these participants may face more liquidity constraints. Thus for them a positive income shock leads to a rapid increase in consumption.

To explore this conjecture, we calculate the mean MPCs for both adjustors and non-adjustors in the stock market. In each period, a household is defined as an adjustor if she re-balances her portfolio. To be clear, adjustors and non-adjustors are identified by their behavior in the absence of the income shock.

Table 11: Income MPC of Consumption Floor Hitters and Stock Market Participants

\begin{tabular}{c|ccc|ccc}
\hline \hline & \multicolumn{3}{|c|}{$1 \%$} & \multicolumn{3}{c}{$10 \%$} \\
\hline & Hitter & Adjustors & Non-adustors & Hitter & Adjustors & Non-adustors \\
\hline Germany & 1.000 & 0.180 & 0.205 & 1.000 & 0.170 & 0.194 \\
Spain & 1.000 & 0.150 & 0.203 & 1.000 & 0.142 & 0.185 \\
France & n.a & 0.114 & 0.176 & n.a. & 0.103 & 0.169 \\
Italy & 1.000 & 0.152 & 0.175 & 1.000 & 0.144 & 0.163 \\
\hline \hline
\end{tabular}

This table reports the mean MPC of consumption floor hitters and stock market participants. Adjustors are the participants who engaged in portfolio re-balancing.

As shown in Table 11, non-adjustors have a higher mean level of MPC in each country, which is consistent with our conjecture. In particular, the MPC of non-adjustors in France is almost $55 \%$ larger than that of adjustors. This 
is then consistent with the finding in Table 10 of higher MPCs for stock market participants with high education and high permanent income.

Finally, while the aforementioned patterns are also seen in the $10 \%$ shock scenario, the numbers are somewhat overall smaller. This reflects the existence of non-linearities with respect to the shock size and is also consistent with the findings of Christelis, Georgarakos, Jappelli, Pistaferri, and van Rooij (2018) who argue that in the presence of liquidity constraints the size of the shock also matters, especially at low levels of economic resources. For large increases in income, consumers are more likely to overcome the constraint (and therefore, the MPC is lower than for small increases).

Table 12: MPC Regressions: Income Shock

\begin{tabular}{|c|c|c|c|c|c|c|c|c|c|c|}
\hline & \multirow[b]{2}{*}{ const. } & \multirow[b]{2}{*}{ age } & \multirow[b]{2}{*}{$a g e^{2}$} & \multirow[b]{2}{*}{ income } & \multirow[b]{2}{*}{$e d u$} & \multicolumn{5}{|c|}{ wealth percentile } \\
\hline & & & & & & $10-50 \%$ & $50-70 \%$ & $70-90 \%$ & $90-95 \%$ & $95-100 \%$ \\
\hline \multicolumn{11}{|c|}{$1 \%$ increase in transitory income } \\
\hline Germany & 0.259 & 0.018 & 0.000 & -0.064 & 0.022 & 0.120 & -0.130 & -0.156 & -0.201 & -0.219 \\
\hline Spain & 0.131 & 0.008 & 0.000 & -0.013 & -0.001 & 0.358 & 0.090 & 0.060 & 0.008 & 0.003 \\
\hline France & 0.341 & 0.014 & 0.000 & -0.040 & -0.012 & -0.046 & -0.192 & -0.245 & -0.258 & -0.262 \\
\hline Italy & 0.300 & 0.019 & 0.000 & -0.068 & -0.022 & 0.032 & -0.213 & -0.237 & -0.275 & -0.282 \\
\hline \multicolumn{11}{|c|}{$10 \%$ increase in transitory income } \\
\hline Germany & 0.219 & 0.018 & 0.000 & -0.056 & 0.020 & 0.096 & -0.136 & -0.162 & -0.206 & -0.223 \\
\hline Spain & 0.109 & 0.008 & 0.000 & -0.007 & 0.001 & 0.325 & 0.089 & 0.061 & 0.008 & 0.003 \\
\hline France & 0.277 & 0.014 & 0.000 & -0.033 & -0.015 & -0.032 & -0.169 & -0.221 & -0.228 & -0.235 \\
\hline Italy & 0.272 & 0.017 & 0.000 & -0.054 & -0.020 & 0.007 & -0.198 & -0.220 & -0.258 & -0.265 \\
\hline
\end{tabular}

This table presents regression results of MPCs in response to positive transitory income shocks of $1 \%$ and $10 \%$, respectively. The dependent variable is the MPC. The explanatory variables are a constant, age, age-squared, income, education (dummy) and wealth percentiles.

Table 12 presents regression results that explain the variations in MPC across households within each country. The dependent variable is the household level MPC as computed above. The explanatory variables are those in the state vector of the dynamic optimization problem. Included are dummies for the household's position in the wealth distribution of that country. The regression has the interpretation of an approximation to (a derivative of) one of the consumption rules.

From these results, there is a slight hump-shape in the MPC, though the variation over the life-cycle is small relative to other household moments. The MPC is falling in income while the effect of education is ambiguous. Note that the big differences across education groups reported in Table 10 are now subsumed by the income and wealth variables.

Most interesting is the nonlinear relationship between the MPC and relative wealth of the household. Here we see that the MPC falls non-linearly with the wealth percentile. This is true for both a $1 \%$ and a $10 \%$ increase in transitory income.

The MPC distribution generated by our model can be compared with that reported in Carroll, Slacalek, and Tokuoka (2014). They report estimates of average MPC values of between $20 \%$ and $40 \%$, when matching the liquid wealth distribution. Of our four countries, their estimate of the aggregate MPC for Germany is lowest at $26 \%$ and 
Spain is the largest at $38 \%$.

The large heterogeneity in MPCs across income and education groups is driven by the non-homotheticity in preferences and the discrete choices of households, as discussed earlier. To quantitatively examine this point, we conduct two experiments. The first experiment sets the consumption floor, the luxuriousness of bequest and the portfolio adjustment costs to zero, thus turning off the potential sources of heterogeneity in MPCs with respect to income. The second experiment further sets the discount factor of the less educated group to be the same as the more educated group, thus making the two groups of households equally patient. The results, for Spain, are reported in Table 18 in the Appendix. The first experiment brings the MPCs of the three permanent income groups within each education group close to each other, indicating that the elements listed above contribute to the non-linearity. The second experiment brings the MPCs of the less educated group down to the levels of the more educated group, indicating that more patience of the better educated households is associated with their lower MPCs.

\subsection{Return Shocks}

Here we study the contemporaneous MPC of households in response to a $1 \%$ and a $10 \%$ shock in the return to stocks. ${ }^{29}$ Note that this shock only affects the choices of households who participate in asset markets. The point of studying both small and large shocks is to understand the non-linearity in response due to the non-convex adjustment costs.

The MPC distribution with respect to these return shocks is reported in Table 13. Higher permanent income or higher education households have lower MPCs on average. The MPCs are essentially independent of the size of the return shock. Importantly, the MPC in the low income and low education cells in Table 13 is not strikingly higher than in the other cells, while the same comparison leads to much larger difference in the case of income shocks in Table 10. This is because the asset market participation rate is very low among households with low income and low education as shown in Table 7, and the small fraction of participants from this group are relatively rich, thus have relatively high MPCs.

Finally, Table 14 presents regression results to summarize how the households' state variables impact the MPC from a stock market return shock. There is no strong dependence of the MPC on age. The MPC falls with both income and with the wealth-to-income ratio, and in general with education.

Our findings are also related to evidence in a recent paper by Di Maggio, Kermani, and Majlesi (2018) that studies the MPC out of stock market returns for Swedish households participating in stock markets. They regress consumption growth on changes in dividends and capital gains. They find that the MPC out of capital gains for households in the top $50 \%$ of the financial wealth distribution is around $5 \%$. On the other hand, it is significantly higher and more than $10 \%$ for the bottom $50 \%$ of the distribution. Note that over $93 \%$ of the stock ownership is by the top $50 \%$.

\footnotetext{
${ }^{29}$ As the return on bonds is deterministic, it makes no sense to explore the response to a zero probability event.
} 
Table 13: MPC Distribution: Return Shocks for Participants

\begin{tabular}{cc|ccc|ccc}
\hline \hline Country & & \multicolumn{3}{|c|}{$1 \%$} & \multicolumn{3}{|c}{$10 \%$} \\
& Ed Inc & low & middle & high & low & middle & high \\
\hline \multirow{2}{*}{ Germany } & low & 0.248 & 0.192 & 0.162 & 0.248 & 0.192 & 0.162 \\
& high & 0.207 & 0.169 & 0.137 & 0.207 & 0.169 & 0.137 \\
Spain & low & 0.328 & 0.177 & 0.160 & 0.328 & 0.177 & 0.160 \\
& high & 0.181 & 0.161 & 0.140 & 0.181 & 0.160 & 0.142 \\
France & low & 0.234 & 0.202 & 0.161 & 0.234 & 0.202 & 0.161 \\
& high & 0.165 & 0.131 & 0.131 & 0.165 & 0.130 & 0.134 \\
Italy & low & 0.367 & 0.170 & 0.160 & 0.367 & 0.170 & 0.160 \\
& high & 0.168 & 0.134 & 0.123 & 0.168 & 0.134 & 0.122 \\
\hline \hline
\end{tabular}

This table summarizes the distribution of MPC from a $1 \%$ and a $10 \%$ return shock for stock market participants. The three columns represent three levels of permanent income. The rows, by country, are for low and high educational attainment for all households as well as those participating in asset markets.

Table 14: MPC Regressions: Return Shocks for Participants

\begin{tabular}{lcccccccccc}
\hline \hline \multicolumn{1}{c}{} & \multicolumn{1}{c}{ const. } & age & age2 & income & edu & $10-50 \%$ & $50-70 \%$ & $70-90 \%$ & $90-95 \%$ & $95-100 \%$ \\
\hline 1\% increase in stock value & & & & & & & \\
\hline Germany & 0.248 & 0.017 & 0.000 & -0.041 & -0.010 & 0.000 & -0.088 & -0.104 & -0.115 & -0.118 \\
Spain & 0.158 & 0.018 & 0.000 & -0.023 & 0.008 & 0.000 & -0.144 & -0.145 & -0.175 & -0.142 \\
France & 0.594 & -0.005 & 0.000 & -0.012 & -0.112 & 0.000 & -0.101 & -0.059 & -0.046 & 0.003 \\
Italy & 0.307 & 0.010 & 0.000 & -0.025 & -0.051 & 0.000 & -0.114 & -0.138 & -0.141 & -0.075 \\
\hline 10\% increase in stock value & & & & & & & & -0.119 \\
\hline Germany & 0.230 & 0.018 & 0.000 & -0.043 & -0.004 & 0.000 & -0.089 & -0.107 & -0.125 \\
Spain & 0.178 & 0.017 & 0.000 & -0.022 & 0.007 & 0.000 & -0.144 & -0.147 & -0.181 & -0.148 \\
France & 0.600 & -0.006 & 0.000 & -0.012 & -0.110 & 0.000 & -0.103 & -0.064 & -0.054 & 0.016 \\
Italy & 0.322 & 0.009 & 0.000 & -0.027 & -0.050 & 0.000 & -0.114 & -0.139 & -0.138 & -0.080 \\
\hline \hline
\end{tabular}

This table presents regression results. The dependent variable is the MPC from a return shock for stock market participants.

The explanatory variables are a constant, age, age-squared, income, the wealth to income ratio and education.

\section{Monetary Policy Implications}

From the above analysis of MPC in response to the income shocks and return shocks, it is clear that the consumption response to shocks is heterogenous across households both within and between countries. ${ }^{30}$ This section turns to the main focus on our study: the dynamic consumption response to monetary innovations.

Let $\tau \geq 0$ be the time since the monetary policy innovation. The effect of a period $t$ monetary policy innovation on aggregate consumption in period $t+\tau$ can be written as:

\footnotetext{
${ }^{30}$ This is emphasized in the analysis of fiscal interventions on European countries in Kaplan, Violante, and Weidner (2014). An analysis of monetary interventions for the US is contained in Kaplan, Moll, and Violante (2018).
} 


$$
\begin{gathered}
\frac{d C_{t+\tau}}{d M P_{t}}=\overbrace{\int_{\Omega} \frac{d c\left(Y, R^{s}, R^{b}, \Omega\right)}{d Y_{t+\tau}(\Omega)} \frac{d Y_{t+\tau}(\Omega)}{d M P_{t}} d G_{t+\tau}(\Omega)}^{\text {Income Channel }}+ \\
\underbrace{\underbrace{}_{\Omega} \frac{d c\left(Y, R^{s}, R^{b}, \Omega\right)}{d R_{t+\tau}^{s}(\Omega)} \frac{d R_{t+\tau}^{s}(\Omega)}{d M P_{t}} d G_{t+\tau}(\Omega)}_{\text {Return Channel }}
\end{gathered}
$$

where $\Omega$ is an index of the individual's state, $Y_{t+\tau}$ is the common component of income in period $t+\tau, R_{t+\tau}^{s}$ is the period $t+\tau$ return on stocks and $d M P_{t}$ denotes a period $t$ monetary innovation. Here $G_{t+\tau}(\Omega)$ is the cross sectional distribution of households over the state space in period $t+\tau$.

Equation (13) summarizes two channels through which a monetary policy innovation impacts aggregate consumption. The first is the response in income created by the monetary innovation. The second is the effect of the monetary innovation on the return to risky assets. ${ }^{31}$ In the following discussion, these are referred to as the "income" and "return" channels. We have studied the MPC distribution in response to a change in income or return independently. But it is important to keep in mind that consumption response through these two channels interact: the decision about portfolio adjustment depends on the total utility gain in response to income and return changes which will generally not be the same as the sum of the utility gain from either of the change independently.

Equation (13) delineates three important dimensions to the policy response. First, the response is individual state dependent. This is made explicit in the income response: $\frac{d Y_{t+\tau}(\Omega)}{d M P_{t}}$ allows the income effect of monetary policy to depend on the individual's state. The effect of the change in the stock returns induced by the innovation will also be individual specific, reflecting both the (endogenous) portfolio composition as well as the magnitude of financial wealth. Second, the response depends on the cross sectional distribution in period $t+\tau, G_{t+\tau}(\Omega)$, for each country. To the extent that the intervention itself changes the cross sectional distribution, there will be an additional dynamic to the policy response. Third, the response is persistent and dynamic, reflecting both the lasting effects of the monetary intervention on income and returns and the evolution of the cross sectional distribution.

Building on the estimated model, we take an empirical approach to study how monetary policy innovations impact the two key channels: income and stock returns. In contrast to these other studies, such as Kaplan, Moll, and Violante (2018), the policy effects on income and interest rates will not be generated by a model. Instead, we take them from empirical analyses of the effects of monetary policy. The analysis is partial in that other effects of the innovation, say on debt obligations and thus on the tax burden that is reduced by a monetary expansion, are ignored.

To be clear, this approach is consistent with a quantitative exercise built upon a stochastic general equilibrium model. In such a model, households would be responding to monetary shocks through a variety of channels, particularly income, returns and taxes. Our approach guarantees that the impulses into the household decision

\footnotetext{
${ }^{31}$ Another channel that accounts for the effect of the policy innovation on the return of the risk free asset is outside of the model since the risk free return is a constant in our model. Further, the impact of interest rate changes on fiscal policy, emphasized in Kaplan, Moll, and Violante (2018), do not appear in our model.
} 
rules are data consistent.

Throughout, we emphasize differences in households within a country as well as differences across countries in the response to policy innovations. In general, the different responses across countries come from the different behavior of households, as seen through the different parameter estimates that lead to the state-contingent MPCs. Further, countries differ in the distributions of households over these states. Finally, there are country-specific elements of the effects of monetary innovations on income and stock returns.

In what follows, we first present the left side of equation (13): the aggregate consumption response to a monetary innovation by country. Next, the aggregate response is decomposed into responses through the income channel and the return channel. Finally, we study the distribution of consumption response across different types of households.

\subsection{Aggregate Impact}

Figure 3 summarizes the impact on consumption of a monetary innovation that reduces the target interest rate by 100 basis points. The top panel of the figure shows the overall response by country to a monetary innovation of a 100 basis point cut in the target rate over 15 years. ${ }^{32}$ Along the vertical axis is the change in consumption relative to the case without any monetary shocks.

There are a few important details underlying the calculation of these responses. First, as described in more detail below, the income and return responses that are inputs into equation (13) are assumed to last for only three periods. But the consumption responses persist for about 15 years in simulation, which comes from the endogenous response of consumption induced by the times series variation in the household's state and its distribution. Second, the 15 year responses come from households that survive the full 15 years of the simulation, and this selection puts more weight on younger households.

For each country, the response is hump-shaped with a peak response in the second year (with the exception of Italy). Regarding the magnitude, at the peak after the monetary shock the consumption levels in Italy and Spain are about $1.25 \%$ higher than the baseline consumption without monetary innovations. At the peak, responses in these two countries are nearly three times of those in France and Germany.

The hump-shaped consumption response is consistent with numerous earlier studies that document a similar pattern for euro-area countries. Smets and Wouters (2005) study an interest rate shock and find a hump-shaped response of consumption in both the US and Europe. The results are also consistent with those for the US reported in Christiano, Eichenbaum, and Evans (2005). For additional evidence on euro area countries, see Figure 3 in Slacalek, Tristani, and Violante (February 2020).

Relative to the results reported in Kaplan, Moll, and Violante (2018), the magnitude of the responses in Italy and Spain are slightly larger than their findings for the US, though the experiments are different. From their Figure 4, a 0.5 annual percentage point increase in consumption following a $0.25 \%$ negative innovation in the quarterly Taylor rule, which mean reverts at a constant rate of $0.5 .{ }^{33}$ That said, there are interesting differences underlying

\footnotetext{
${ }^{32}$ As before, these are calculated based upon a simulation using the initial distribution of asset holdings from the data and then averaging over aggregate return shocks to obtain a cross sectional distribution, conditional on age.

${ }^{33}$ Roughly speaking, over a year, their shock is half of ours and the response is also nearly half of ours.
} 
Figure 3: Dynamic Consumption Response to a Monetary Shock
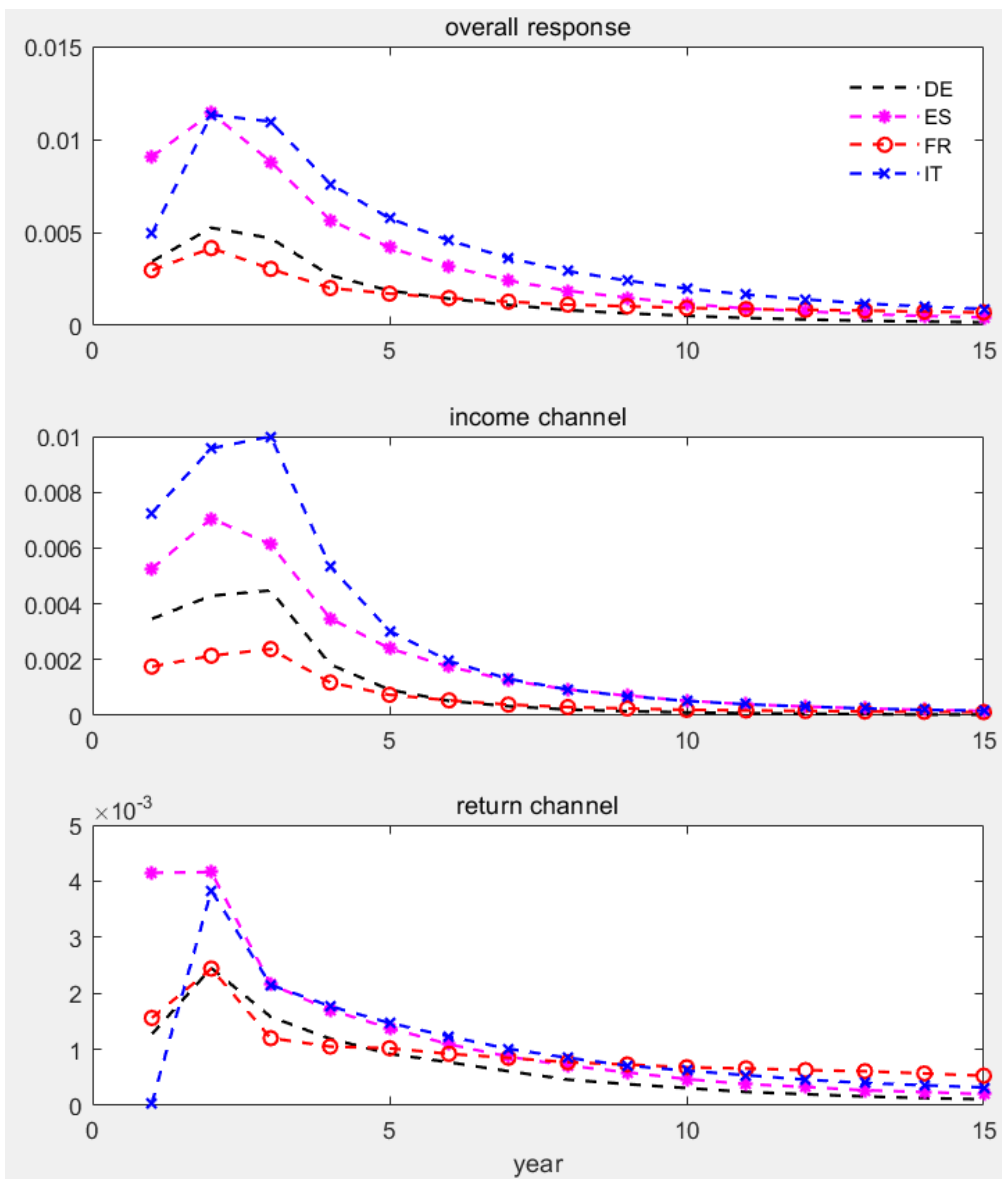

This figure shows the aggregate consumption response over time to a 100 basis point decrease in the target rate based on the estimated model for each of the four European countries. The vertical axis measures the percent change in consumption relative to the case of no intervention.

the total response. As in our results, the main channel of response is through labor income. But, in our setting a second major channel is through the effect of monetary policy on stock returns. This channel is negligible in their model. For some countries, such as Spain, we find that the component due to changes in returns is more than a third of the entire consumption response. As noted earlier, our analysis omits the response of fiscal transfers to monetary innovations, which is a large part of the response in the Kaplan, Moll, and Violante (2018) analysis. In this way, the relative importance of the channels differs across the studies.

It is important to understand how these simulated responses depend on the parameter estimates. To study this, we take the baseline response of France to a monetary shock and compare it against the response created by imposing the estimated parameters for Italy on their French counterparts. This is obviously one of many ways to see how the responses to monetary policy depend on the parameters. Instead of picking arbitrary variations, this exercise highlights differences across countries. So, for example, the estimated $\gamma$ of 21.308 for France is substituted 
by the estimate of 8.255 for Italy. Then the household optimization problem is re-solved using the new parameter, and the effects of a monetary shock are re-simulated.

For this exercise, we identify three parameters that have a large impact on the consumption response of France: $(\gamma, \theta, \beta)$. The top panel of Figure 4 illustrates the effects. Reducing the risk aversion from the French to the Italian estimates has a large impact on the consumption response. The period 1 consumption response increases from $0.3 \%$ to $0.41 \%$. As indicated in the figure, consumption remains higher throughout the simulation. Likewise, imposing the larger estimate of $\theta$, the EIS, on France also leads to a larger consumption response, but not of the magnitude of the reduction in the risk aversion. Finally, using the Italian estimates of the discount factors, which are larger than those estimated for France, also has a large impact. As indicated in the figure, the increase in patience led to a more persistent consumption response to monetary innovations relative to the baseline response.

Figure 4: France Consumption Response to a Monetary Shock
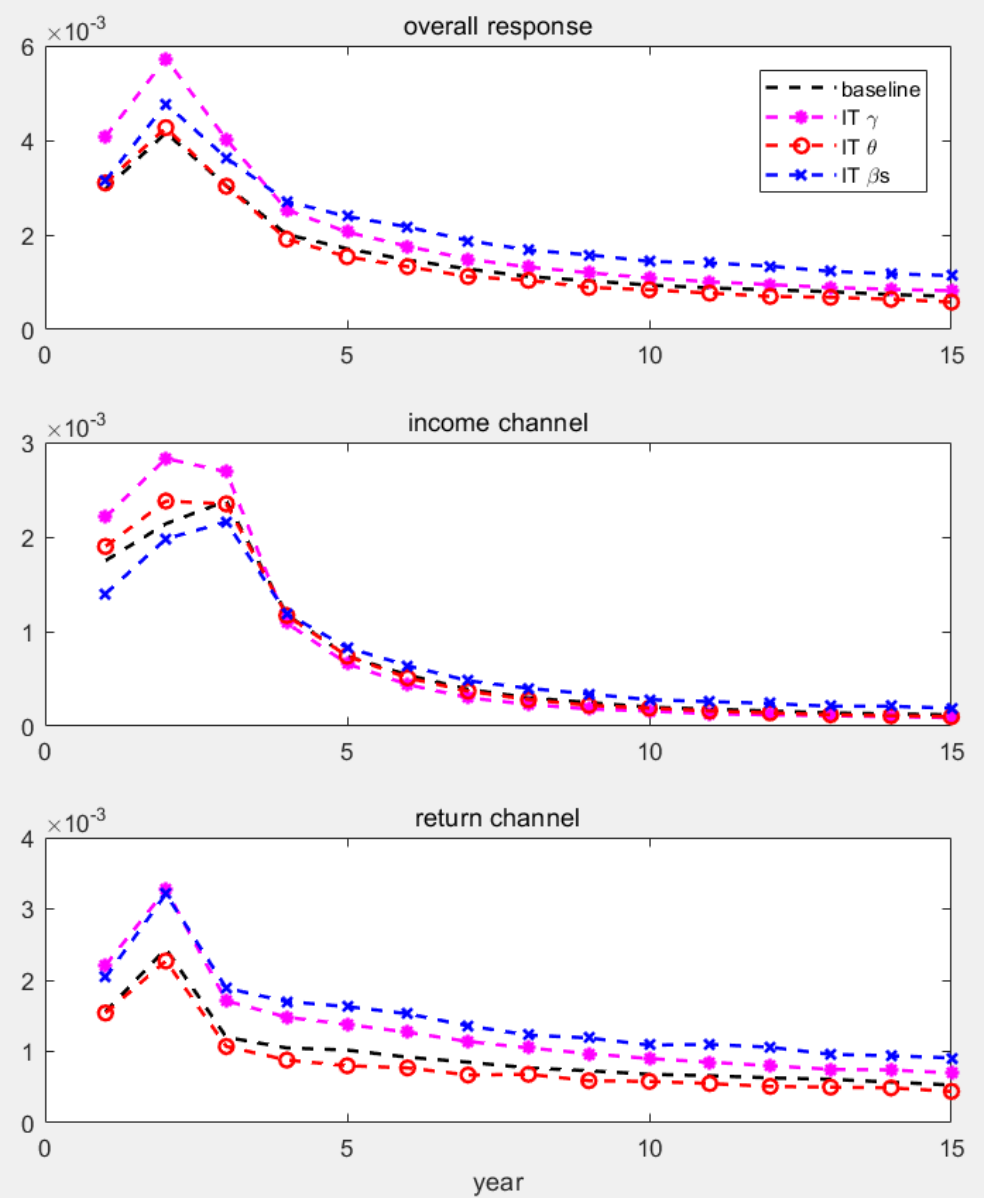

This figure shows the aggregate consumption response in France over time to a 100 basis point decrease using the the estimated values of $\gamma, \theta$ and $\beta$ s for Italy, along with the baseline results that use France's own parameter values The vertical axis measures the percent change in consumption relative to the case of no intervention. 


\subsection{Income Channel}

Evaluating the effects on consumption of monetary policy through the income channel requires two steps. Both of these components are country-specific so that the consumption responses to monetary policy through the income channel vary by country.

The first step is to determine the responses of income to the monetary innovations. ${ }^{34}$ We take the responses from Lenza and Slacalek (2018), displayed in their Figure 4, and are summarized in Table 15. These responses combine the effects of monetary innovations on wages and on the probability of employment. ${ }^{35}$ Note that the responses are heterogenous in that the income effects differ based upon the household's income quintile. The income response to monetary innovations is much larger in Spain, particularly for the lowest income quintile. Table 15 also indicates that the response of income to monetary innovations are persistent. Since the largest responses come in the first two to three years, we feed into the simulation only three years of income changes shown in the table. In the simulation we have three income groups, with the low and the high income groups corresponding to the lowest and highest income quintiles in the table, and the middle income group corresponding to quintiles 2 to 4 .

Table 15: Monetary Policy Effect on Income in the Data

\begin{tabular}{cc|cccc}
\hline \hline Income Quintile & Year & DE & FR & ES & IT \\
\hline 1 & 1 & 3.39 & 1.49 & 8.21 & 3.57 \\
& 2 & 3.25 & 1.55 & 7.87 & 2.62 \\
2 & 3 & 3.17 & 1.25 & 6.70 & 1.26 \\
& 1 & 0.87 & 0.94 & 2.35 & 3.15 \\
& 2 & 0.87 & 0.94 & 2.34 & 2.51 \\
3 & 3 & 0.87 & 0.70 & 1.85 & 1.05 \\
& 1 & 0.34 & 0.88 & 1.68 & 2.51 \\
& 2 & 0.34 & 0.88 & 1.68 & 2.30 \\
4 & 3 & 0.34 & 0.64 & 1.52 & 1.05 \\
& 1 & 0.29 & 0.45 & 1.01 & 2.09 \\
& 2 & 0.30 & 0.45 & 1.01 & 2.09 \\
5 & 3 & 0.30 & 0.45 & 1.01 & 1.48 \\
& 1 & 0.15 & 0.45 & 0.68 & 1.87 \\
& 2 & 0.15 & 0.45 & 0.67 & 1.88 \\
& 3 & 0.15 & 0.45 & 0.68 & 1.05 \\
\hline
\end{tabular}

This table reports the response of household income to a 100 basis point monetary policy rate reduction by income quintile in year 1 , year 2 and year 3 , respectively. Numbers are taken from Lenza and Slacalek (2018), combining the effect on wages and employment.

The second step is to determine the response of consumption to the change in income. This is also state dependent since, as illustrated above, there are ample MPC heterogeneities. For this response, we take the income

\footnotetext{
${ }^{34}$ This builds upon the study of Italian households in Casiraghi, Gaiotti, Rodano, and Secchi (2018). Discussions on this with Marco Casiraghi are much appreciated.

${ }^{35}$ Specifically, it is assumed that households who move from unemployment to employment increase their income by a percentage determined by the inverse of the prevailing net replacement rate in their country. Then these responses are combined with the responses of wages according to the proportion in the population of households moving from unemployment to employment and those already employed and just increasing their wage.
} 
changes given by Table 15 as exogenous changes to the transitory income in the model, and re-compute the policy functions, then we use the new policy functions to simulate consumption responses at the household level and the aggregate level. ${ }^{36}$

The results are summarized by the middle panel of Figure 3. Clearly, the consumption response is the largest in Italy, more than twice that of Germany and almost three times that of France. Consumption responses through the income channel are all hump-shaped.

One might conjecture that the hump-shape is driven by the assumed three-year responses of income to monetary innovations. To study this, we conduct the experiments where the income response lasts for only one year. Results are shown in Figure 5 which indicates that the hump-shaped responses remain. Thus the humps and persistence of the consumption responses are partly driven by the endogenous evolution of the asset holdings by the heterogenous households.

Figure 5: Consumption Response to a Monetary Shock: One Year Income Shock

Consumption Response

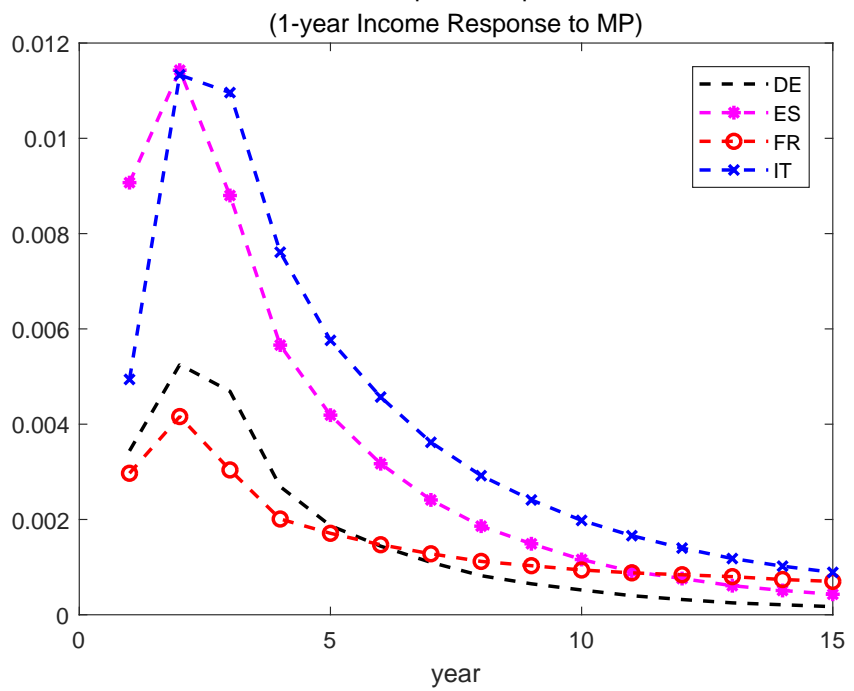

This figure shows the aggregate consumption response over time to a 100 basis point decrease, assuming that income response to monetary innovations only happens contemporaneously. The vertical axis measures the percent change in consumption relative to the case of no intervention.

Figure 6 reports consumption responses of different permanent income groups. For each country, clearly the low income group has the largest consumption response, and the response is significantly larger in Italy. This is consistent with the observation in Table 15 that the lowest income quintile has the largest income effect of monetary innovations, particularly for Italy and Spain.

Returning to the discussion of the French response with some Italian parameters, the middle panel of Figure 4 shows the differential response through the income channel alone. The patterns of the response are very similar to those shown in the top panel. But there are large differences in magnitude. Imposing the Italian risk aversion on

\footnotetext{
${ }^{36}$ In this formulation, households do not distinguish an income variation due to a monetary innovation from a standard transitory shock. The consumption response will be larger if we have treated the income changes as persistent income shocks.
} 
Figure 6: Consumption Response to a Monetary Shock (income channel)
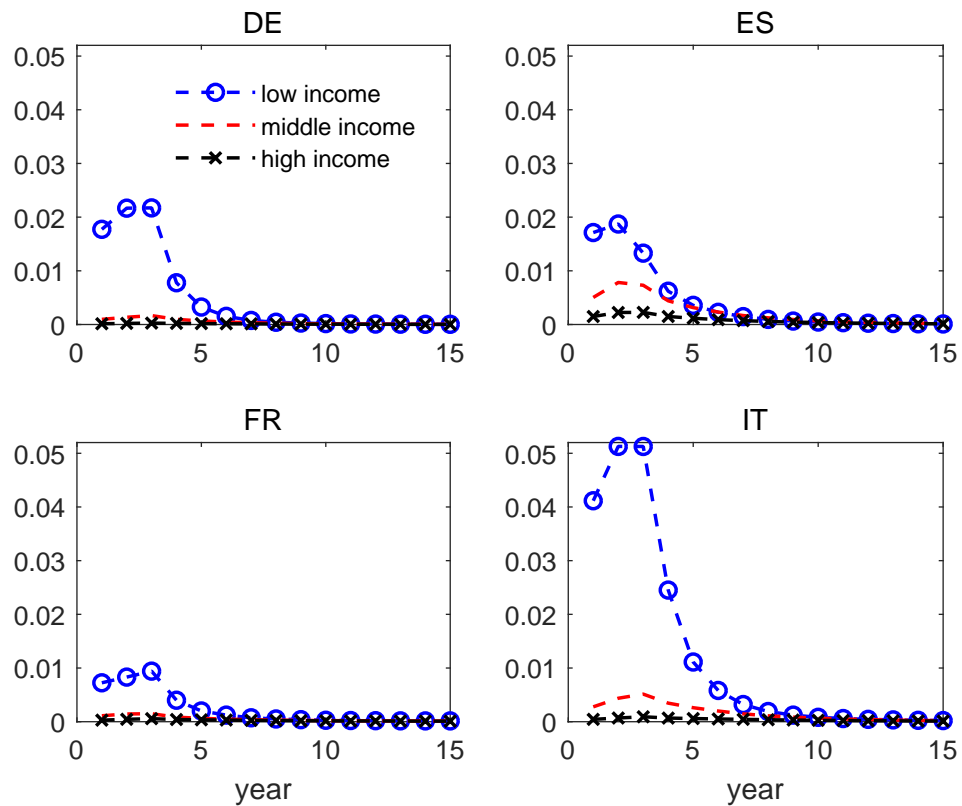

This figure shows the consumption response of different income groups to a 100 basis point decrease in the target rate through the income channel based on the estimated model for each country.

the French model increases the consumption response the most, while imposing the Italian discount factors which represent more patience reduces the consumption response in France.

\subsection{Return Channel}

This section studies return channel of consumption response to monetary innovation. In general, these responses reflect both the participation rates in the stock market and the consumption response to variations in returns, governed in part by the elasticity of substitution parameter, $\theta$.

We study this channel also in two steps. First, there is a country-specific VAR which determines the impact of monetary policy innovations on stock returns. ${ }^{37}$ The details of the procedure to uncover these responses are provided in Appendix 9.2. ${ }^{38}$ The second step evaluates how the return shocks leads to consumption responses over time.

The impulse response functions showing how stock returns react to monetary policy innovations are shown in Figure 7 and discussed in more detail in the Appendix. The underlying estimation is based upon quarterly data. It is interesting to note that the immediate response of the stock market to expansionary policy is for the returns to decrease. This is often interpreted as a reaction to the informational content of the intervention. ${ }^{39}$ By the end of the first year there is a sizable, positive response of real stock prices in all four countries.

\footnotetext{
${ }^{37}$ Here we broadly follow the analysis in Lettau, Ludvigson, and Steindel (2002).

${ }^{38}$ We are grateful to Sebastian Rast for his preparation of these impulse responses.

${ }^{39}$ Relatedly, output actually contracts in the impact period as well.
} 
Figure 7: Stock Return Response to a Monetary Shock in the Data
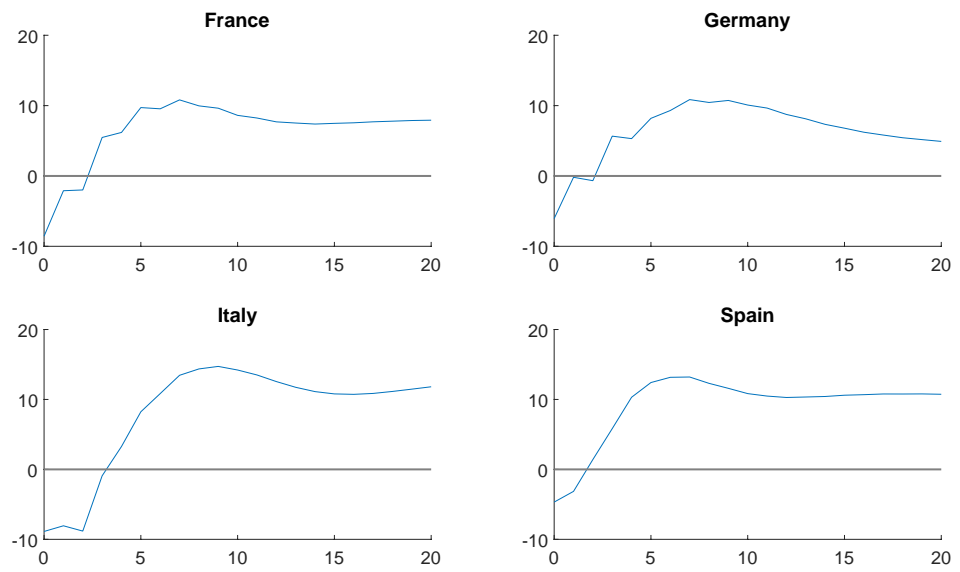

This figure shows the quarterly response of real stock price in terms of percentage changes to a monetary policy shock based on data over the period 1999 Q1-2018 Q4.

In addition to the heterogenous response of returns by country, households within each country are influenced differently as well based upon their asset market participation status and the size of their financial holdings. These differences are present in the earlier calculations of the MPC after a return shock as shown in Table 13. The overall consumption responses by country are shown in the bottom panel of Figure 3.

These responses of consumption to monetary innovations is strikingly different from the model created responses reported in Kaplan, Moll, and Violante (2018). ${ }^{40}$ In particular, as seen in Figure 4 of Kaplan, Moll, and Violante (2018), the response to asset returns is negligible. This reflects two offsetting influences. The lower rates increase assets values through standard discounted present value calculations. But, at the same time, profits are countercyclical in the model and thus asset values fall. Evidently these effects essentially cancel and thus asset returns respond very little in the Kaplan, Moll, and Violante (2018) model to monetary innovations. ${ }^{41}$

The bottom panel of Figure 4 shows how the consumption response in France is changed from imposing some of the Italian parameters, through the return channel. Once again, the changes in the risk aversion have the largest impact on consumption. Also imposing the larger discount factors of Italy on France leads to more persistence in the response.

\subsection{Distributional Effects}

An additional perspective on the effects of monetary policy is to look at the total effect through both channels on particular groups in the population. The analysis further establishes an important theme: monetary policy impacts the relatively poor households through the income channel and the relatively rich households through the return channel. The implication is that the overall consumption response is larger for the two extremes of the income

\footnotetext{
${ }^{40}$ Conversations with Gianluca Violante have been very helpful to our understanding these differences.

${ }^{41}$ From Christiano, Eichenbaum, and Evans (2005), real profits increase in response to a monetary innovation.
} 
distribution. ${ }^{42}$

It is natural to partition households into groups based upon education and permanent income, along the lines of Tables 9 and 10. The top panel of Table 16 summarizes the effects of monetary policy on these households. The bottom panel aggregates over education in order to highlight the difference across income groups. These numbers are the averages of the consumption response in the first three years after a monetary innovation.

Looking at the income channel alone, the impact of monetary policy on consumption is decreasing in income, for both education groups. This again reflects the effects of the policy on income by quintile and the relatively high MPC of low income groups. This is seen in the "Income Channel" panel of the table.

For the return channel, the picture is just the opposite. This is seen in the "Return Channel" panel of the table which reports consumption responses of asset market participants. Here households with low income and low education have negligible consumption responses except in Spain. This is because only a small fraction of this group participates in asset markets and the participants are selected to be relatively wealthy, thus their consumption are less responsive to return shocks. The high income and high education group participates more in asset markets, and the participants are more responsive to return shocks.

The income channel and return channel decomposition explains a U-shaped consumption response to monetary innovations, which is shown in the right panel of the table that shows the overall consumption response. An innovation largely affects low and high income households, but in very different ways. The low income households are sensitive to the monetary innovation through the income channel, thus the consumption response is large. The high income households participate more in asset markets and thus have financial income that is sensitive to monetary innovations through the return channel, so is their consumption.

Importantly, the total effect is not simply the sum of effects from the two channels. This reflects the inherent non-linearities in the problem. For example, the two channels together might induce portfolio adjustment though no such adjustment arises in response to one independent channel. Further, some wealthy households save more when the higher income is accompanied by a high stock return, thus their aggregate consumption response is smaller relative to response when they received only income shocks.

\section{Conclusion}

This paper uses a life-cycle framework to study household financial choices and their implications for the effects of monetary policy on aggregate consumption, emphasizing the importance of participation in stock markets and stock adjustment choices. The country-specific model parameters are estimated via a simulated method of moments approach, using moments that highlight the life-cycle patterns in household financial choices.

The estimation uncovers the presence of asset market participation costs as well as portfolio adjustment costs. The estimated discount factors lie between 0.75 and 0.80 for low education households to between 0.85 and 0.90

\footnotetext{
${ }^{42}$ As emphasized in Auclert (2017), these distributional aspects, particularly the income effects operating through high MPC households, serves to amplify the affects of monetary policy interventions.
} 
Table 16: Consumption Response to a Monetary Shock

\begin{tabular}{|c|c|c|c|c|c|c|c|c|c|c|}
\hline \multirow[t]{2}{*}{ Country } & \multirow[b]{2}{*}{ Ed } & \multicolumn{3}{|c|}{ Income Channel } & \multicolumn{3}{|c|}{ Return Channel } & \multicolumn{3}{|c|}{ Overall } \\
\hline & & low & middle & high & low & middle & high & low & middle & high \\
\hline \multirow[t]{2}{*}{$\overline{\mathrm{DE}}$} & low & 2.113 & 0.118 & 0.016 & 0.052 & 0.240 & 0.436 & 0.723 & 0.475 & 0.562 \\
\hline & high & 1.975 & 0.079 & 0.011 & 0.091 & 0.403 & 0.707 & 0.759 & 0.564 & 0.785 \\
\hline \multirow[t]{2}{*}{$\mathrm{ES}$} & low & 2.819 & 0.826 & 0.231 & 0.472 & 0.575 & 0.798 & 2.473 & 1.403 & 1.127 \\
\hline & high & 1.429 & 0.407 & 0.110 & 0.590 & 0.802 & 0.937 & 1.676 & 1.219 & 1.085 \\
\hline \multirow[t]{2}{*}{$\mathrm{FR}$} & low & 1.078 & 0.167 & 0.052 & 0.020 & 0.186 & 0.394 & 0.626 & 0.375 & 0.476 \\
\hline & high & 0.372 & 0.044 & 0.019 & 0.193 & 0.493 & 0.711 & 0.388 & 0.550 & 0.735 \\
\hline \multirow[t]{2}{*}{ IT } & low & 6.472 & 0.410 & 0.070 & 0.263 & 0.243 & 0.351 & 2.027 & 0.656 & 0.289 \\
\hline & high & 3.576 & 0.202 & 0.029 & 0.181 & 0.372 & 0.378 & 1.250 & 0.365 & 0.214 \\
\hline $\mathrm{DE}$ & all & 2.056 & 0.102 & 0.014 & 0.068 & 0.307 & 0.548 & 0.738 & 0.512 & 0.655 \\
\hline $\mathrm{ES}$ & all & 2.432 & 0.709 & 0.197 & 0.505 & 0.638 & 0.837 & 2.251 & 1.352 & 1.115 \\
\hline $\mathrm{FR}$ & all & 0.827 & 0.124 & 0.040 & 0.082 & 0.296 & 0.507 & 0.541 & 0.437 & 0.568 \\
\hline IT & all & 6.130 & 0.386 & 0.065 & 0.253 & 0.258 & 0.354 & 1.935 & 0.621 & 0.280 \\
\hline
\end{tabular}

This table summarizes the consumption response in percentage from a monetary shock (100 basis points increase in interest rate). The bottom panel aggregates over education groups.

for high education households. These estimates are well below traditional calibrations, but they lead to wealth-toincome ratios from the model that are consistent with the data.

The estimated model has implications for the distributions of MPCs in response to transitory income shocks and stock return shocks. Within a country these distributions are not degenerate due to household heterogeneity. Further, the MPC distribution is country-specific, driven by differences in estimated parameters across countries and in the exogenous processes of income and stock return. Generally, the MPC is higher for low income, low education households. The relatively small fraction of liquidity-constrained asset market participants (non-adjustor) also has large MPCs.

After analyzing the distribution of MPCs in response to income shocks and return shocks, we characterize both the average and distributional effects of monetary innovations on consumption through two channels: (i) the nonasset income channel and (ii) the stock return channel. Due to the distributional effects, differences in consumption responses across countries are obvious. Overall, Spain has the largest response to monetary innovations through the return channel while Italy has the largest response through the income channel. When the two channels are combined, the aggregate response of consumption to a monetary innovation is the largest in Italy and smallest in France.

Our analysis identifies a number of factors that are relevant for the transmission of monetary policy. For example, counterfactual experiments show that the small consumption response to monetary innovations in France is partly driven by the estimated large coefficient of risk aversion and low elasticity of intertemporal substitution. More generally, countries differ in their preference parameters, stock market participation costs and adjustment costs, and response of income to monetary shocks. The combined effects of these differences lead to drastically different consumption responses to monetary shocks. This should help policy makers evaluate ex-ante the potential effects of monetary policy decisions.

To be clear, we focus on two monetary policy channels in our model, namely, the income channel and the 
stock return channel. Other influences of monetary innovation, for example, spending by households and firms on durables, are potentially important and should be considered in a future extension.

\section{References}

Alan, S. (2006): "Entry Costs and Stock Market Participation over the life cycle," Review of Economic Dynamics, $9,588-611$.

Ampudia, M., D. Georgarakos, J. Slacalek, O. Tristani, P. Vermeulen, and G. Violante (2018): "Monetary policy and household inequality," European Central Bank Working Paper \#2170.

Auclert, A. (2017): "Monetary policy and the redistribution channel," Discussion paper, National Bureau of Economic Research, forthcoming American Economic Review.

Bonaparte, Y., R. Cooper, and G. Zhu (2012): "Consumption Smoothing and Portfolio Rebalancing: The Effects of Adjustment Costs," Journal of Monetary Economics, 59, 751-68.

Bonin, H., T. Dohmen, A. Falk, D. Huffman, and U. Sunde (2007): "Cross-Sectional earnings risk and occupational sorting: The role of risk attitudes," Labour Economics, 14, 926-37.

Calvet, L., J. Campbell, F. Gomes, and P. Sodini (2016): "The Cross-Section of Household Preferences," mimeo.

CARroll, C. (1992): "The buffer-stock theory of saving: Some macroeconomic evidence," Brookings papers on economic activity, 1992(2), 61-156.

Carroll, C. D., J. Slacalek, and K. Tokuoka (2014): "The Distribution of wealth and the MPC: implications of new European data," The American Economic Review, 104(5), 107-111.

Casiraghi, M., E. Gaiotti, L. Rodano, and A. Secchi (2018): "A 'Reverse Robin Hood'? The distributional implications of non-standard monetary policy for Italian households," Journal of International Money and Finance, 85, 215-235.

Chamberlain, G. (1984): Panel Data,chap. 22, pp. 1274-1381. Amsterdam, North Holland.

Christelis, D., D. Georgarakos, and M. Haliassos (2013): "Differences in portfolios across countries: Economic environment versus household characteristics," Review of Economics and Statistics, 95(1), 220-236.

Christelis, D., D. Georgarakos, T. Jappelli, L. Pistaferri, and M. van Rooij (2018): "Asymmetric Consumption Effects of Transitory Income Shocks," The Economic Journal, forthcoming.

Christiano, L. J., M. Eichenbaum, and C. L. Evans (2005): "Nominal rigidities and the dynamic effects of a shock to monetary policy," Journal of political Economy, 113(1), 1-45. 
Cloyne, J., C. Ferreira, and P. Surico (2020): "Monetary policy when households have debt: new evidence on the transmission mechanism," The Review of Economic Studies, 87(1), 102-129.

Cocco, J. F., F. J. Gomes, and P. J. Maenhout (2005): "Consumption and portfolio choice over the life cycle," Review of Financial Studies, 18(2), 491-533.

Coibion, O., Y. Gorodnichenko, L. Kueng, and J. Silvia (2017): "Innocent Bystanders? Monetary policy and inequality," Journal of Monetary Economics, 88(C), 70-89.

Cooper, R., And G. Zhu (2015): "Household Finance: Education, Permanent Income and Portfolio Choice," Review of Economic Dynamics, 20, 63-89.

Deaton, A. (1991): "Saving and Liquidity Constraints," Econometrica, 59(5), 1221-48.

Denardi, M., E. French, and J. B. Jones (2010): "Why Do the Elderly Save? The Role of Medical Expenses," Journal of Political Economy, 118(1), 39-75.

Di Maggio, M., A. Kermani, and K. Majlesi (2018): "Stock Market Returns and Consumption," Discussion paper, Lund University.

Epstein, L., And S. ZIN (1989): "Substitution, risk aversion, and the temporal behavior of consumption and asset returns: A theoretical framework," Econometrica: Journal of the Econometric Society, pp. 937-969.

Fagereng, A., C. Gottlieb, and L. Guiso (2017): "Asset market Participation and Portfolio Choice over the Life Cycle," The Journal of Finance, 72(2), 705-750.

Garbinti, B., P. Lamarche, C. Lecanu, and F. Savignac (2020): "Wealth effect on consumption during the sovereign debt crisis: households heterogeneity in the euro area," ECB Working Paper.

Gomes, F., and A. Michaelides (2005): "Optimal life-cycle asset allocation: understanding the empirical evidence," Journal of Finance, 60(2), 869-904.

Guerrieri, C., And C. Mendicino (2018): "Wealth Effects in the Euro Area," mimeo.

Guiso, L., M. Haliassos, and T. Jappelli (2003): "Household stockholding in Europe: where do we stand and where do we go?," Economic Policy, 18(36), 123-170.

Guiso, L., and M. Paiella (2006): Insurance: Theoretical Analysis and Policy,chap. The role of risk aversion in predicting individual behavior. MIT Press.

(2008): "Risk Aversion, Wealth and Background Risk," Journal of the European Economic Association, $6,1109-50$.

Guvenen, F. (2009): “An Empirical Investigation of Labor Income Process," Review of Economic Dynamics, 12, $58-79$. 
Hansen, L. P. (1982): "Large Sample Properties of Generalized Methods of Moments Estimators," Econometrica, $50,1029-1054$

Hintermaier, T., and W. Koeniger (2018): "Differences in euro-area household finances and their relevance for monetary-policy transmission," CESifo Working Paper \#7088.

Hubbard, G., J. Skinner, and S. Zeldes (1994): "The Importance of Precautionary Saving in Explaining Individual and Aggregate Savings," in Carnegie-Rochester Conference Series on Public Policy, pp. 59-105.

Hubbard, R., J. Skinner, and S. Zeldes (1995): "Precautionary Saving and Social Insurance," Journal of Political Economy, 103(2), 360-399.

Jappelli, T., And L. Pistaferri (2014): "Fiscal policy and MPC heterogeneity," American Economic Journal: Macroeconomics, 6(4), 107-36.

Kaplan, G., B. Moll, and G. L. Violante (2018): "Monetary Policy According to HANK," American Economic Review, 108(3), 697-743.

Kaplan, G., G. Violante, and J. Weidner (2014): "The Wealth Hand-to-Mouth," Brookings Papers on Economic Activity, pp. 77-138.

Kaplan, G., and G. L. Violante (2014): "A model of the consumption response to fiscal stimulus payments," Econometrica, 82(4), 1199-1239.

Krusell, P., And A. A. Smith, JR (1998): "Income and wealth heterogeneity in the macroeconomy," Journal of political Economy, 106(5), 867-896.

Laibson, D., A. Repetto, and J. Tobacman (2001): "A Debt Puzzle," Working Paper 7879, National Bureau of Economic Research.

Le Blanc, J., and D. Georgarakos (2013): "How Risky is Their Income? Labour Income Processes in Europe," Goethe University Frankfurt.

Lenza, M., And J. SlacaleK (2018): "How does monetary policy affect income and wealth inequality? Evidence from the euro area," mimeo.

Lettau, M., S. Ludvigson, and C. Steindel (2002): "Monetary policy transmission through the consumptionwealth channel," FRBNY Economic Policy Review, 5, 117-133.

Slacalek, J., O. Tristani, and G. Violante (February 2020): "Household Balance Sheet Channels of Monetary Policy: A Back of the Envelope Calculation for the Euro Area," ECB.

Smets, F., And R. Wouters (2005): "Comparing shocks and frictions in US and euro area business cycles: a Bayesian DSGE approach," Journal of Applied Econometrics, 20(2), 161-183. 
Vissing-Jorgensen, A. (2002): "Towards an explanation of household portfolio choice heterogeneity: Nonfinancial income and participation cost structures," NBER Working Paper \#8884.

WeIL, P. (1990): "Nonexpected utility in macroeconomics," The Quarterly Journal of Economics, 105(1), 29-42.

\section{Appendix}

\subsection{Additional Findings}

Additional finding are reported here. Table 17 provides the standard errors for the data moments used in the estimation.

Table 8 shows the elasticity of moments to parameters for Spain, at the baseline parameters. This table is useful for intuition about identification.

Table 18 studies the factors that contribute to the nonlinearity of the MPC. This is for Spain.

Table 17: Standard Errors of Data Moments

\begin{tabular}{|c|c|c|c|c|c|c|}
\hline & & con. & age & $\overline{a g e^{2}}$ & $\begin{array}{c}\text { college } \\
(* \text { age })\end{array}$ & $\underset{* \text { age }^{2}}{\text { college }}$ \\
\hline \multirow[t]{3}{*}{ Germany } & Part. & 0.030 & 0.0012 & 0.00001 & 0.007 & \\
\hline & Share & 0.003 & 0.0001 & 0.000001 & 0.001 & \\
\hline & $\mathrm{W} / \mathrm{I}$ & 0.211 & 0.0085 & 0.00008 & 0.004 & 0.00006 \\
\hline \multirow[t]{3}{*}{ Spain } & Part. & 0.027 & 0.0011 & 0.00001 & 0.006 & \\
\hline & Share & 0.004 & 0.0002 & 0.00000 & 0.001 & \\
\hline & $\mathrm{W} / \mathrm{I}$ & 0.459 & 0.0177 & 0.00016 & 0.007 & 0.00012 \\
\hline \multirow[t]{3}{*}{ France } & Part. & 0.015 & 0.0006 & 0.00001 & 0.004 & \\
\hline & Share & 0.001 & 0.0001 & 0.00000 & 0.000 & \\
\hline & $\mathrm{W} / \mathrm{I}$ & 0.124 & 0.0049 & 0.00004 & 0.003 & 0.00005 \\
\hline \multirow[t]{3}{*}{ Italy } & Part. & 0.023 & 0.0008 & 0.00001 & 0.006 & \\
\hline & Share & 0.005 & 0.0002 & 0.00000 & 0.001 & \\
\hline & $\mathrm{W} / \mathrm{I}$ & 0.336 & 0.0123 & 0.00010 & 0.007 & 0.00011 \\
\hline
\end{tabular}

\subsection{Monetary Innovations and Stock Returns}

For each country a separate VAR is estimated over the period 1999 Q1 -2018 Q4 using data on the HICP index, GDP, stock price index and Eonia. The HICP index and GDP are used in log-levels and Eonia in levels. The stock price index is deflated by the HICP index and log-first differences are taken to obtain a measure of real stock returns.

The structural VAR can be written as

$$
B_{0} z_{t}=k+B_{1} z_{t-1}+B_{2} z_{t-2}+\ldots+B_{p} z_{t-p}+u_{t}
$$


Table 18: The Nonlinearity of MPCs (Spain)

\begin{tabular}{|c|c|c|c|c|c|c|c|}
\hline & & \multicolumn{3}{|c|}{ All Households } & \multicolumn{3}{|c|}{ Participants } \\
\hline & & low & middle & high & low & middle & high \\
\hline \multirow[t]{2}{*}{ baseline } & low & 0.684 & 0.338 & 0.222 & 0.327 & 0.250 & 0.211 \\
\hline & high & 0.306 & 0.191 & 0.150 & 0.226 & 0.178 & 0.150 \\
\hline \multirow[t]{2}{*}{$\underline{c}=\phi=F=0$} & low & 0.653 & 0.722 & 0.724 & 0.188 & 0.196 & 0.238 \\
\hline & high & 0.592 & 0.577 & 0.611 & 0.103 & 0.086 & 0.129 \\
\hline \multirow[t]{2}{*}{$\underline{c}=\phi=F=0$, and $\beta_{0}=\beta_{1}$} & low & 0.589 & 0.595 & 0.604 & 0.081 & 0.090 & 0.104 \\
\hline & high & 0.592 & 0.577 & 0.611 & 0.103 & 0.086 & 0.129 \\
\hline
\end{tabular}

This table shows the MPCs for Spain under different assumptions. When setting the parameters that cause non-linearity to zeros, households in different income groups have very similar MPCs. If in addition, the discount factor of the low education group is set to the same level as the high education group, then the MPCs are similar across different education groups.

where $z_{t}=\left[\pi_{t}, y_{t}, R_{t}^{S}\right.$, Eonia $\left.t\right]$ defined as described above and we set the number of lags $\mathrm{p}$ to 4 . The monetary policy shock is identified by putting restrictions on the matrix $B_{0}$. We follow a similar approach as Ludvigson et al. (2002) and apply the following nonrecursive identifying assumption on $B_{0}$

$$
B_{0}=\left[\begin{array}{cccc}
1 & 0 & 0 & 0 \\
\beta_{21} & 1 & 0 & 0 \\
\beta_{31} & \beta_{32} & 1 & \beta_{34} \\
\beta_{41} & \beta_{42} & 0 & 1
\end{array}\right]
$$

The VAR is estimated using maximum likelihood estimation.

Summary Table The following table summarizes the stock market response to monetary policy obtained from the 4 VARs estimated for France, Germany, Italy and Spain. The shock to the Eonia is normalized to a 1 percentage point increase on impact. The first row for every country corresponds to the estimates that come directly out of the VAR which includes deflated/real stock market returns. Overall the response of stock market returns is very volatile, maybe due to the relatively short sample period. Therefore, the second row for every country shows a centered three-quarter moving average of the response of stock market returns. The third row for every country contains the cumulative sum of the effect on returns, i.e. the change in the deflated stock price index.

IRFs The detailed responses of all variables are shown in figures 8-9. The shock to the Eonia is normalized to a 1 percentage point increase on impact and the responses of the other variables are multiplied by 100 to be interpreted as percent change. Moreover, for illustrative reasons the bottom left chart shows the cumulative sum of real stock return response which can be interpreted as the percentage change in the deflated stock market index. 
Table 19: Real/Deflated Stock Market Response to 1 pp. Increase in Eonia

\begin{tabular}{l|c|c|c|c|c|c|c|c|c}
\hline Quarter & 0 & 1 & 2 & 3 & 4 & 5 & 6 & 7 & 8 \\
\hline France: Stock returns & 0.086 & -0.065 & -0.001 & -0.075 & -0.007 & -0.035 & 0.002 & -0.013 & 0.008 \\
France: 3 quarter MA & 0.011 & 0.007 & -0.047 & -0.028 & -0.039 & -0.013 & -0.015 & -0.001 & -0.001 \\
France: Stock price & 0.086 & 0.021 & 0.02 & -0.055 & -0.062 & -0.097 & -0.095 & -0.108 & -0.1 \\
\hline Germany: Stock returns & 0.061 & -0.059 & 0.005 & -0.063 & 0.004 & -0.029 & -0.011 & -0.016 & 0.004 \\
Germany: 3 quarter MA & 0.001 & 0.002 & -0.039 & -0.018 & -0.029 & -0.012 & -0.019 & -0.008 & -0.005 \\
Germany: Stock price & 0.061 & 0.002 & 0.007 & -0.056 & -0.052 & -0.081 & -0.092 & -0.108 & -0.104 \\
\hline Italy: Stock returns & 0.089 & -0.008 & 0.008 & -0.079 & -0.042 & -0.05 & -0.026 & -0.026 & -0.009 \\
Italy: 3 quarter MA & 0.041 & 0.03 & -0.026 & -0.038 & -0.057 & -0.039 & -0.034 & -0.02 & -0.013 \\
Italy: Stock price & 0.089 & 0.081 & 0.089 & 0.01 & -0.032 & -0.082 & -0.108 & -0.134 & -0.143 \\
\hline Spain: Stock returns & 0.047 & -0.015 & -0.046 & -0.044 & -0.045 & -0.021 & -0.007 & 0 & 0.009 \\
Spain: 3 quarter MA & 0.016 & -0.005 & -0.035 & -0.045 & -0.037 & -0.024 & -0.009 & 0.001 & 0.005 \\
Spain: Stock price & 0.047 & 0.032 & -0.014 & -0.058 & -0.103 & -0.124 & -0.131 & -0.131 & -0.122 \\
\hline
\end{tabular}


Figure 8: Response to a Monetary Shock
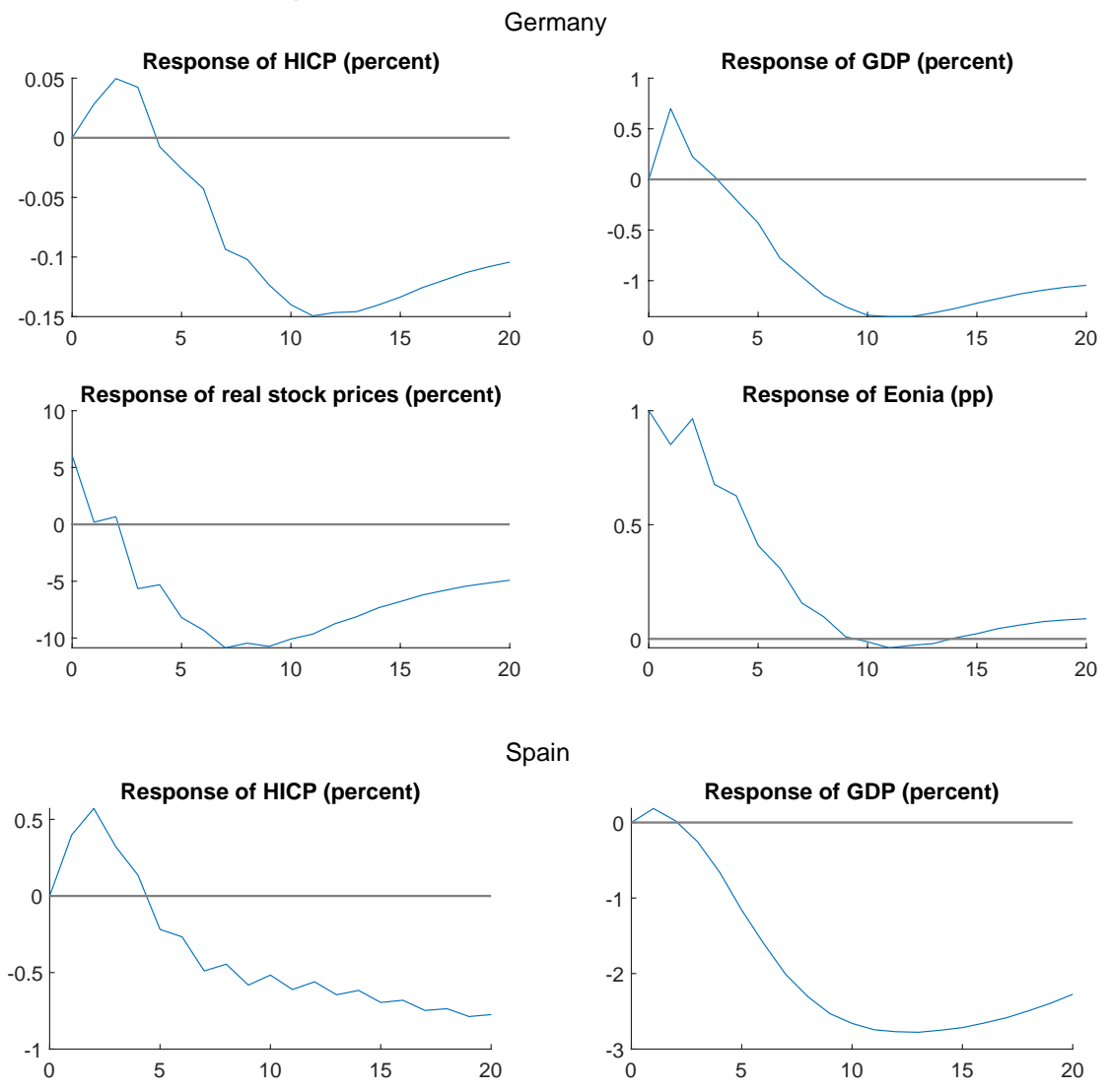

Spain
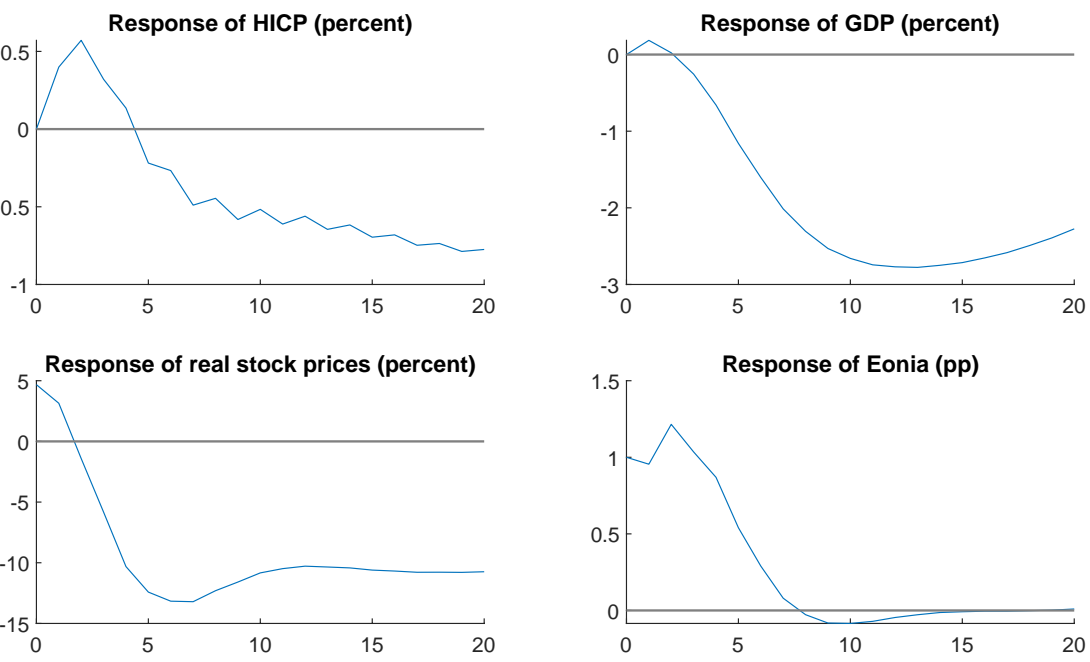
Figure 9: Response to a Monetary Shock

Italy
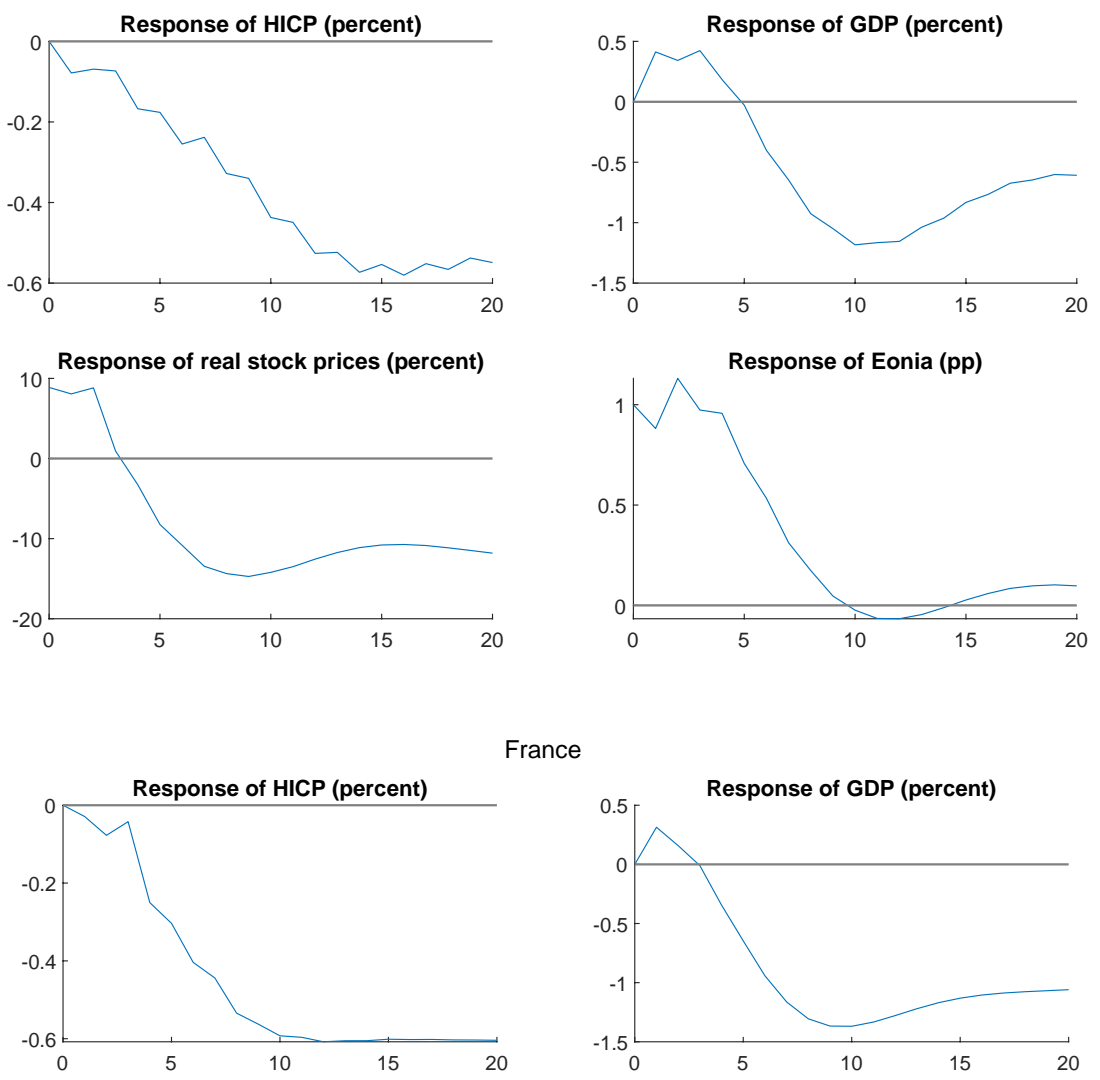

France
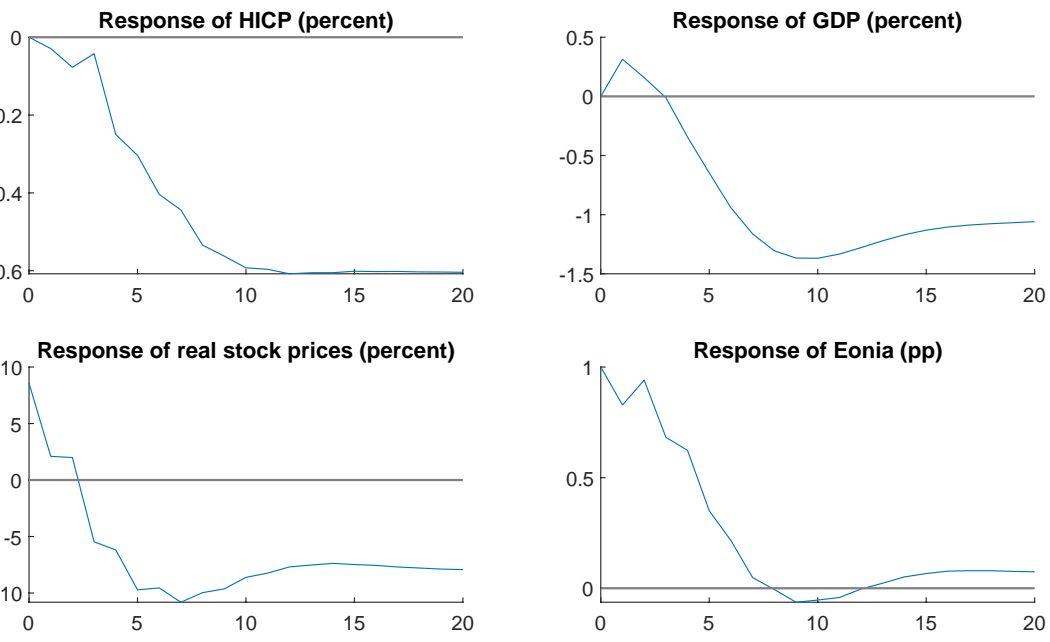


\begin{tabular}{|c|c|c|c|c|c|}
\hline & & 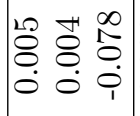 & $\left|\begin{array}{lll}0 & 0 & 1 \\
\hdashline & \delta & 0 \\
0 & 0 & 0 \\
0 & 0 & 0 \\
0\end{array}\right|$ & 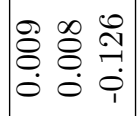 & $\begin{array}{l}\hat{\delta} \\
\dot{0} \\
\dot{0}\end{array}$ \\
\hline & $\exists$ & $\mid \begin{array}{lll}\sharp & 0 & \Re \\
\delta & 0 & 0 \\
0 & 0 & 0 \\
0 & 0 & 0 \\
0\end{array}$ & 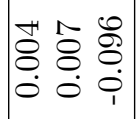 & 15 & $\begin{array}{ll}3 & 19 \\
8 & 8 \\
0 & 0 \\
0 & 0\end{array}$ \\
\hline & 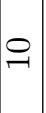 & $\begin{array}{lll}- & 0 & 1 \\
0 & 0 & 0 \\
0 & 0 & 0 \\
0 & 0 & 0 \\
0 & 0 & 1\end{array}$ & $\mid \begin{array}{ccc}1 & 9 & -1 \\
0 & 0 & -1 \\
0 & 0 & 0 \\
0 & 0 & 1\end{array}$ & $\begin{array}{l}2 \\
0 \\
0 \\
0\end{array}$ & $\begin{array}{ll}\infty & 0 \\
0 & 8 \\
0 & 0 \\
0 & 0\end{array}$ \\
\hline & & 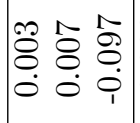 & 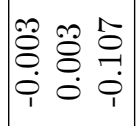 & 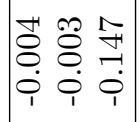 & $\begin{array}{l}1 \\
8 \\
0\end{array}$ \\
\hline & $\infty$ & $\left|\begin{array}{ccc}\infty & -1 & -1 \\
0 & 8 & -1 \\
0 & 0 & 0 \\
0 & 0 & 1\end{array}\right|$ & 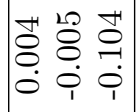 & 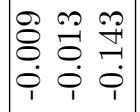 & $\begin{array}{ll}8 & 2 \\
8 & 8 \\
0 & 0 \\
0\end{array}$ \\
\hline & & $\begin{array}{lll}m & -1 & \infty \\
0 & 0 & 0 \\
0 & 0 & 0 \\
0 & 0 & 0 \\
1 & 1 & 1\end{array} \mid$ & $\begin{array}{lll}0 & \infty & \infty \\
0 & 0 & 0 \\
0 & 0 & 0 \\
0 & 0 & -1 \\
1 & 0 & 0 \\
1 & 1 & 1\end{array} \mid$ & 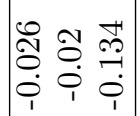 & o \\
\hline & 6 & 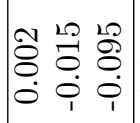 & 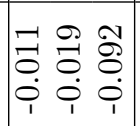 & 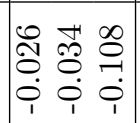 & $\begin{array}{ll}1 & 0 \\
0 & 0 \\
0 & 0 \\
0 & 0 \\
1\end{array}$ \\
\hline & & \begin{tabular}{lll}
20 & 0 & 0 \\
\hdashline & $\ddot{0}$ & 0 \\
0 & 0 & 0 \\
0 & 0 & 0 \\
1 & 1 & 1
\end{tabular} \mid & $\left|\begin{array}{lll}2 & 0 & \overrightarrow{1} \\
0 & 0 & 0 \\
0 & 0 & 0 \\
0 & 0 & 0 \\
1 & 1 & 1\end{array}\right|$ & 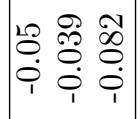 & 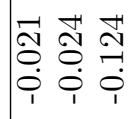 \\
\hline & $\forall$ & 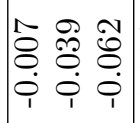 & 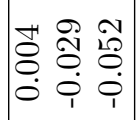 & 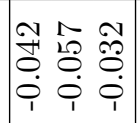 & $\begin{array}{ll}10 & 1 \\
0 & 0 \\
0 & 0 \\
0 & 0 \\
1 & 0\end{array}$ \\
\hline & $\infty$ & $\left|\begin{array}{ccc}12 & 0 & 2 \\
1 & 0 & 0 \\
0 & 0 & 0 \\
0 & 0 & 0 \\
1 & 1 & 0 \\
1 & 1\end{array}\right|$ & $\left|\begin{array}{lll}\Re & \infty & 0 \\
0 & 0 & 0 \\
0 & 0 & 0 \\
0 & 0 & 0 \\
1 & 1 & 1\end{array}\right|$ & $\left|\begin{array}{ccc}0 & \infty & \\
0 & 0 & 0 \\
0 & 0 & 0 \\
0 & 0 & 0 \\
1 & 1 & 0\end{array}\right|$ & 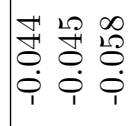 \\
\hline & $\sim$ & 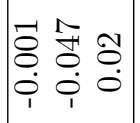 & 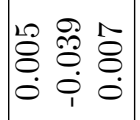 & 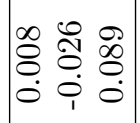 & $\begin{array}{l}0 \\
0 \\
0 \\
0 \\
i\end{array}$ \\
\hline & -1 & 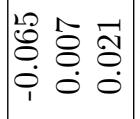 & 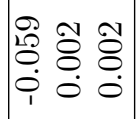 & $\mid \begin{array}{lll}\infty & \infty & - \\
0 & 0 & \infty \\
0 & 0 & 0 \\
1 & 0 & 0\end{array}$ & $\begin{array}{lll}20 & 20 & 0 \\
0 & 0 & 0 \\
0 & 0 & 0 \\
0 & 0 & 1\end{array}$ \\
\hline & 0 & $\left|\begin{array}{ccc}0 & -1 & 0 \\
\infty & F & \infty \\
0 & 0 & 0 \\
0 & 0 & 0 \\
0\end{array}\right|$ & 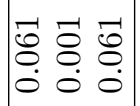 & $\left|\begin{array}{lll}0 & - & 0 \\
\infty & \not{J} & \infty \\
0 & 0 & 0 \\
0 & 0 & 0\end{array}\right|$ & 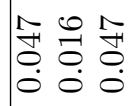 \\
\hline & 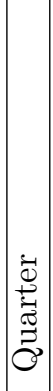 & 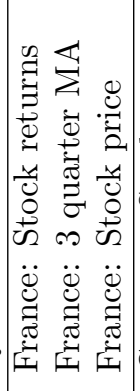 & 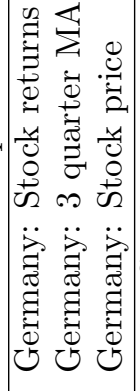 & 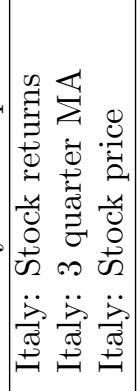 & 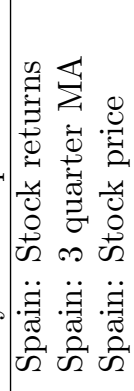 \\
\hline
\end{tabular}

